\author{
Maestría en Economía \\ Facultad de Ciencias Económicas \\ Universidad Nacional de La Plata
}

TESIS DE MAESTRIA

\author{
ALUMNO \\ Juan Matías Sanchez
}

TITULO

Financiamiento Universitario y Bienestar: Un Análisis Dinámico con Agentes Heterogeneos y Generaciones Superpuestas

DIRECTOR

Emilio Espino

FECHA DE DEFENSA

$6 / 27 / 2003$ 


\title{
An Economic Analysis of Higher Education Financing Policies*
}

\author{
Juan M. Sanchez ${ }^{\dagger}$
}

October, 2004

\begin{abstract}
This paper develops a model in which it is possible to evaluate alternatives of higher education financing. The alternative systems under discussion are: total feeing, graduates' taxes and uniform taxes (this can be associated to the scheme presently used in the Argentina to finance the Universities).

Assessment of the alternatives is performed over welfare, based on the indicators of poverty, equality, and the average levels of utility and wealth. Likewise, the functions of welfare presented by Bentham, Rawls, Atkinson, Sen and Kakwani are also considered.

The most remarkable results are obtained through the simulation of an economy under two scenarios. In that way, the system of graduates' taxation is found to be better for welfare; whereas the system of uniform taxation only can be justified as it maximizes the number of students.
\end{abstract}

JEL classification: H1, I2, E62, O15

Keywords: Human Capital, Welfare, Overlapping Generations

\footnotetext{
*This paper was prepared as Thesis for the Master in Economics at UNLP. I would like to specially thank the most valuable participation of the Director of the Thesis, Emilio Espino, during the whole investigation. I also appreciate those comments from Maria E. Cañón, two anonymous referees and the participants to the Seminar of Economy at the UNLP and the Meeting of the Network on Inequality and Poverty (NIP), LACEA (Argentine chapter). Remaining errors are exclusively my responsibility.

${ }^{\dagger}$ Graduate Student at the Department of Economics of the University of Rochester. Email: sncz@troi.cc.rochester.edu. Address: 216 University Park, Rochester, NY, 14620, US.
} 


\section{Introduction}

In the last years, there were opinions given by international education organizations asking for some reform on the Universities' financing system. Such as it is cited by Ennis and Porto (2001), J.C. Tedesco (Director of the International Institute for Education Planning of the UNESCO) stated that "what is really dramatic is that the university -a fundamental institution in the processes of production and distribution of knowledge- does not assume the debate over the necessary reform that will make the changes deep, speedy and in the direction demanded by the current situation in the country... The University owes the society this debate'. In the same direction, the sociologist J.J. Brunner stated that "what should be done is to go beyond the myths and say overtly that a free university generates inequity. If we do not, it will be very difficult to try to conceive some more reasonable policy to finance our institutions of higher education'. ${ }^{1}$ In addition, Jacques Attali -former advisor to President François Mitterrand and chairperson of a committee that proposed new structures for higher education in France- made some interesting comments with reference to the functioning of Latin American universities. According to Attali: 'some universities have chosen to be the best in the world and for that reason they are obligated to select not only the best teachers but also the best students in the world. The rest of the universities -mass universities- are no more than a camouflage of unemployment'. ${ }^{2}$

From the economic point of view, it is clearly seen that even though supporters of each of the systems can be really enthusiastic about them, there is no theory from which they stem. ${ }^{3}$ Particularly, there is no single model that can show that sustaining public university is desirable or that it could be better to establish any of the other alternatives. This omission is relevant due to the possible lack of problems associated with the present system and the need to offer some theoretical or explanatory model that can possibly deal with the advantages of the alternative systems.

In general, the economic study of educational aspects has been started out of three perspectives. The first one has been to consider education as a consumption decision. The second one has been to approach education as a signal of the individuals' unseen capacity. Finally, the perspective to be used in this study will be to consider education as a decision of investment in human capital.

\footnotetext{
${ }^{1}$ 'Clarín' Newspaper, February 2002.

${ }^{2}$ As quoted in 'La Nación', September 6, 2002.

${ }^{3}$ The term theory is used as Lucas (1988): 'I prefer the term theory in a very narrow sense, to refer to an explicit dynamic system, something that can be put on a computer and run'.
} 
There are models or theories available which are part of the literature on investment in human capital and whose seminal work is Becker (1962). They can be separated, according to Aghion and Howitt (1998), into two structures or frameworks. The first one is the 'Lucas approach'4 in which growth is achieved through the accumulation of human capital; the second is the 'Nelson and Phelps approach'5 where growth is mainly understood through the human capital stock.

Within this classification, the present work belongs to the 'Lucas approach'. For that reason, Glomm and Ravikumar (1992) and Galor and Zeira (1993) are the necessary reference.

Glomm and Ravikumar (1992) present a model of overlapping generations with heterogeneous agents. The latter can differ in their incomes and abilities. Within this framework, endogenous human capital investment in a system of formal education is the driver of growth. The main results obtained are the following: (a) income inequality, as measured by its variance, shows a greater fall under a system of public education; (b) higher per-capita incomes results from private education, except when the initial inequality is 'extremely high'; (c) societies with most of their agents with incomes below average will opt for the public education system.

Galor and Zeira (1993) analyze how income and wealth distribution are related to long-term macroeconomic issues, such as growth and adjustment among sectors, by means of the inclusion of investment in human capital and inter-generational altruism. This is analyzed in a model of overlapping generations where agents can be differentiated form each other on the sole basis of their initial wealth. In general terms, this analysis showed that initial distributions of wealth and income affect product and investment in the short and long terms.

Following by analogy to Lucas (1988), rather than offer you some of our opinions about human capital financing in Argentina, we simply made a system and let you watch it unfold. The organization of our work is as follows. First, in section 2, the model of overlapping generations with heterogeneous agents in relation to their abilities (tendency to work) and inheritance is presented. The structure of the model, the dynamics, the equilibrium and the steady state in the case of total fees (the basic case) are described. After that, solutions are found to the different systems of financing (uniform taxation and graduates taxation). The fourth section compares the previously mentioned alternatives. In the first place, results from the steady state are compared. After that, a numerical example is developed and results related

\footnotetext{
${ }^{4}$ Due to Lucas (1988).

${ }^{5}$ Due to Nelson and Phelps (1966).
} 
to equality, poverty, levels of utility, wealth and welfare (defined through several functions) are found. Section 5 discusses the basic assumptions. The last section presents some comments for Argentina. Appendix A presents all the proofs and Appendix B some figures.

\section{The Model}

A model in which it will be possible to evaluate the implications over welfare of the alternative systems for financing investment in human capital is introduced in this section.

The model introduced here makes use of an analytical structure similar to that of Galor and Zeira (1993) in which different systems of human capital financing might be analyzed. Unlike Galor and Zeira (1993), heterogeneity is added to the abilities of the agents in order to try to improve the adjustment of this model to reality. In addition, the present work differs from Galor and Zeira (1993) in the subject of investigation. Chiu (1998) use a similar but more general framework to analyze the effect of income redistribution on human capital accumulation. Romero (2004), in a similar framework, analyses how the size of the subsidy is endogenously determined by a political economy's mechanism.

Although the present model is used in this context to analyze alternatives for financing higher education, it is so general that it can also be used in other contexts. For example, deciding to invest may be interpreted as an investment to participate in the formal sector of the economy in which salaries are higher.

However, this model has certain peculiarities that allow us to associate it with a context in which alternatives for higher education are studied. Contrary to Caucutt and Kumar (2000) who studied schemes of subsidies for education in the US, in the present model, the decision of investing is taken by the agents that will attend

university other than their parents. Note that the latter is more likely true in the case of university education. Besides, the difference between studying and not studying can be associated to the difference between professionals and not professionals, which is more unlikely to occur in other levels of education.

\subsection{Framework}

In each generation there is a continuum of agents of size 1. Each generation lives two periods. Each of the agents has a child, for which reason the size of the population is 
constant. Those agents born in $t$, live together in $t+1$ with their children (who are born at the beginning of this period). That is the reason why it is said that there are overlapping generations in the model.

The use of overlapping generations is very convenient because it allows for an analysis of cohorts (Browning, Hansen and Heckman, 1999). As it will be seen in this case, the analysis will be focused on the evolution of the distributions of wealth and utility of the generations. At the same time, the study of two overlapping generations is an abstract to study those groups in detail. In order to think about the economy of reality, it could be reinterpreted as if there were many groups in which the same happened.

There is only one consumption good that can be produced with two alternative technologies. There is perfect competition in the market of goods and factors.

The first technology makes use of labor only by uneducated people (unskilled work). Production with this technology in the period $t$ is $Y_{t}^{u}$. Under equilibrium $w_{u}$ is the salary of unskilled workers which is supposed to be constant.

The other technology makes use of labor only from educated people (skilled work). Production with this technology in the period $t$ is $Y_{t}^{s}$. Under equilibrium, $w_{s}$ is the salary of skilled workers. However, skilled workers are differentiated by variable $\beta_{i}$, so the skilled worker $i$ obtains $\beta_{i} w_{s}$.

$\beta_{i}$ is a variable that differs among the agents and that represents the abilities and/or the tendency to effort of the agent. This variable reflects the performance at work and for that reason it is said to be constituted by innate abilities such as tendency to make efforts (both an agent who is ready to work focused every hour in the day and a very intelligent agent would give a very high value for this variable).

It is important that $\beta_{i}$ is correlated across generations. We adopt, such as Acemoglu (2001) and Romero (2004), a particularly simple form of this here, and assume that the type of agents do not change across generations, i.e., $\beta_{i, t}=\beta_{i, t-1}$ for each $i$ and for each $t$.

The agent $i$ knows the value of $\beta$ from his birth. For this reason it is considered when deciding whether to invest in human capital or not. ${ }^{6}$

It will be taken that $\beta_{i}$ takes values in the interval $\left[\beta_{\min }, \beta_{\max }\right]$, in relation to the

\footnotetext{
${ }^{6}$ Note that as $\beta$ is known, there is no uncertainty over the performance of education. In Rillaers and Durán (2002) the decision of investing in human capital is taken under uncertainty over performance.
} 
distribution $L(\beta)$ determined in period 0 , with a function of density $l(\beta)$, so that

$$
\int_{\beta_{\min }}^{\beta_{\max }} l(\beta) d \beta=1 .
$$

Thus, an agent born in the period $t$ has two options: (a) to work both periods as a unskilled worker (in $t$ and $t+1$ ) or (b) to invest in human capital (education) when young (in $t$ ) and work as a skilled worker when he is grown-up (in $t+1){ }^{7}$

Members from the same dynasty are related by inheritance since the agents derive profits from the inheritance left to their children. Such as it is stated by Mulligan (1997), parents will decide on how to divide their resources between themselves and their children. Since parents will be influenced by the economic success of their children, they would like to pass onto them such resources that might contribute to that objective. However, not all their resources are passed on to their children due to the fact that the desire for the progress of the latter is balanced with the desire of spending on themselves.

Thus, the preferences of an agent born in the period $t$ are represented by

$$
u_{t i}\left(c_{t+1 i}, b_{t i}\right)=\alpha \ln c_{t+1 i}+(1-\alpha) \ln b_{t i},
$$

where $c_{t+1}$ is consumption when being an old person in $t+1$ (does not consider consumption when young) and $b_{t}$ is the inheritance left onto their children that will be born at the beginning of $t+1$ (during $t+1$ lives together with their children).

Agents are endowed with 1 unity of time in each period ${ }^{8}$ and with the wealth they inherit from their parents. That is to say, if $x_{t}$ is the initial wealth of an agent born in $t$, so $x_{t}=b_{t-1}$ where $b_{t-1}$ is the inheritance left by their parents. The variable $x_{t}$, which will be called wealth, will have a distribution in $t$ that will be referred to as $F_{t}$ with a function of density $f_{t}$ (note that $f_{0}$ is the function of initial density of wealth for generation 0, which is supposed to be continuous). In this way, we wil have that

$$
\int_{0}^{\infty} f_{t}(x) d x=1 \text { for all } \mathrm{t} .
$$

It should be also noted in the same way that those agents born in the period $t$, live at the time as their parents who were born in $t-1$. In this way, the population in the period $t$ will be

$$
\int_{0}^{\infty} f_{t-1}(x) d x+\int_{0}^{\infty} f_{t}(x) d x=2 .
$$

\footnotetext{
${ }^{7}$ Note that investment in human capital is indivisible, as in Galor and Zeira (1993).

${ }^{8}$ Given that inutility of work or utility of leisure are not considered here, the agents will definitely devote their endowment of time to study or work. Leisure is incorporated, for example, in Glomm and Ravikumar (1992).
} 
As from the function of wealth distribution $(F(x))$ and the ability-tendency to make efforts $(L(\beta))$, which are independent during the period 0 , there is a function of joint distribution over $(x, \beta)$, that will be called $M(x, \beta)$.

We will assume that agents are able to place any quantity at the international rate $r$. However, due to some reasons related to imperfections in the international market of credits, if they are willing to go into debt, they will have to pay interest rates $i>r$. This is due to the monitoring of investments in intangible assets. ${ }^{9}$ This assumption is not very strong since, such as Ennis and Porto (2001) point out, the market of credits for students is often virtually non-existent. Moreover, other studies, as Chiu (1998) and Romero (2004), assume that there is not credit market.

Agents maximize their utility. Supposing that $y_{t}$ is the income at the end of period $t+1$ of an agent born in $t$, they will be able to decide on their consumption and their optimum inheritance. For this reason, the problem of the agent is

$$
\underset{c_{t+1}, b_{t}}{\operatorname{Max}} \alpha \ln c_{t+1 i}+(1-\alpha) \ln b_{t i} \text { s.t. } \quad y_{t}=c_{t+1}+b_{t} .
$$

From the Lagrangean and the FOC, it is possible to operate in order to obtain,

$$
c_{t+1}=\alpha y_{t} \quad ; \quad b_{t}=(1-\alpha) y_{t}
$$

The homotheticity of the relation consumption-inheritance in relation to the income, such as it is used here, is being discussed by Mulligan (1997) who presents a model in which he makes altruism endogenous. Consequently, in his analysis the proportion of wealth that parents leave to their children is not independent from the level of income.

Investment in human capital when agents are young costs $h$, which represents both the direct expenditures (such as fees) and the indirect ones (that is to say, accommodation expenses, books, etc.). ${ }^{10}$ Such as it is stated by Galor and Zeira (1993) in order to lead the system towards a steady state from any initial distribution it will be necessary to suppose that the minimum income that a skilled worker can generate is higher than the one that he can obtain working both periods as a nonskilled one and placing $h$ at the interest rate $r{ }^{11}$

\footnotetext{
${ }^{9}$ This characteristic of the financial market is equal to Galor and Zeira (1993).

${ }^{10}$ Since the literature over university financing has pointed out the need to make 'knowledge public', the present work -so as not to get involved in this discussion- introduces the alternatives over how to finance human capital and does not make reference to more or less public and private sector intervention.

${ }^{11}$ Note that in accordance to this assumption, if the market of capitals were perfect, there would not be restriction to studying deriving from the initial wealth and even the agent with $\beta_{\text {min }}$ would choose to study.
} 
Assumption 1: $\beta_{\min } w_{s} \geq w_{u}(2+r)+h(1+r)$.

Likewise, it is supposed that the active interest rate is 'higher enough' than the passive rate.

Assumption 2: $(1-\alpha)(1+i)>1>(1-\alpha)(1+r)$.

\subsection{Equilibrium}

There will be three kinds of agents in the equilibrium of each period, according to their decision of investing in human capital and the possibility of financing that investment with their own resources. They will be defined in relation to their utility and inheritance as follows.

Definition 1 Those who will not invest in human capital (unskilled) and will work as unskilled during both periods. For them, the level of utility will be $U^{u}$ and the inheritance will be $b^{u}$. In this case their level of utility will be

$$
U^{u}=\ln \left[\left(x+w_{u}\right)(1+r)+w_{u}\right]+\varepsilon
$$

where $\varepsilon=\alpha \ln \alpha+(1-\alpha) \ln (1-\alpha)$. At the same time it is possible to find the inheritance that parents leave to their children,

$$
b^{u}=(1-\alpha)\left[\left(x+w_{u}\right)(1+r)+w_{u}\right] .
$$

Definition 2 Those with $x_{t} \geq h$ that will invest in human capital and will lend. For them, the level of utility will be $U^{\text {sl }}$ and the inheritance will be $b^{s l}$,

$$
\begin{gathered}
U^{s l}=\ln \left[w_{s} \beta+(x-h)(1+r)\right]+\varepsilon \\
b^{s l}=(1-\alpha)\left[w_{s} \beta+(x-h)(1+r)\right] .
\end{gathered}
$$

Definition 3 Those who, even when having $x<h$ will invest in human capital borrowing what they lack at the interest rate $i$. For them, the level of utility will be $U^{s b}$ and the inheritance will be $b^{s b}$,

$$
\begin{gathered}
U^{s b}=\ln \left[w_{s} \beta+(x-h)(1+i)\right]+\varepsilon \\
b^{s b}=(1-\alpha)\left[w_{s} \beta+(x-h)(1+i)\right] .
\end{gathered}
$$


Under each period, the decision of investing in human capital will be made taking into account the initial wealth $(x)$ and the ability / tendency to make efforts $(\beta)$, as a whole. Those who are better off will be more likely to study due to the fact that they will not need to borrow any money, and that investment will be profitable based on assumption 1. Similarly, those who are 'more skillful-hardworking' will require a lower level of initial wealth since their future returns will be higher.

In this way, a value of $x$ in function of $\beta$ will be found, by means of which agents will decide in favor of investing in human capital, doing $U^{u}=U^{s l}$.

Lemma 1 There is for each dynasty a $q$ in function of $\beta$,

$$
q(\beta)=\frac{\left[w_{u}(2+r)+(1+i) h-w_{s} \beta\right]}{i-r},
$$

so that its members will invest in education as long as their initial wealth obtained as inheritance is higher.

Once $q(\beta)$ is known, it is possible to compute the quantity of agents who decide in favor of studying and those who decide against it. It is for that reason that the function of density conditioned to $\beta$ is previously defined as $m(x \| \beta)$ and the function of joint distribution conditioned to the values of $\beta$ as $M(x \| \beta)$.

Those qualified from the generation born in $t$ will be those who will have $x$ higher than $q(\beta)$ for all the possible values of $\beta$,

$$
\begin{gathered}
P_{t}=\int_{\beta_{\min }}^{\beta_{\max }} \int_{q_{t}(\beta)}^{\infty} m_{t}(x \| \beta) d x d \beta \\
=\int_{\beta_{\min }}^{\beta_{\max }}\left[1-M_{t}\left(q_{t}(\beta) \| \beta\right)\right] d \beta .
\end{gathered}
$$

The complement $\left(1-P_{t}\right)$ will be those who do not qualify in $t$.

\subsection{Dynamics}

Once the structure of the model and the equilibrium during each period are known it is possible to find out what the dynamics of individual's wealth will be like. It will be clearly seen that the three types of agents have different dynamics, as follows,

$$
x_{t+1}\left\{\begin{array}{l}
b^{u}\left(x_{t}\right)=(1-\alpha)\left[\left(x_{t}+w_{u}\right)(1+r)+w_{u}\right] \quad \text { if } x_{t}<q(\beta) \\
b^{s b}\left(x_{t}\right)=(1-\alpha)\left[w_{s} \beta+\left(x_{t}-h\right)(1+i)\right] \quad \text { if } q(\beta) \leq x_{t}<h \\
b^{s l}\left(x_{t}\right)=(1-\alpha)\left[w_{s} \beta+\left(x_{t}-h\right)(1+r)\right] \quad \text { if } h \leq x_{t}
\end{array} .\right.
$$




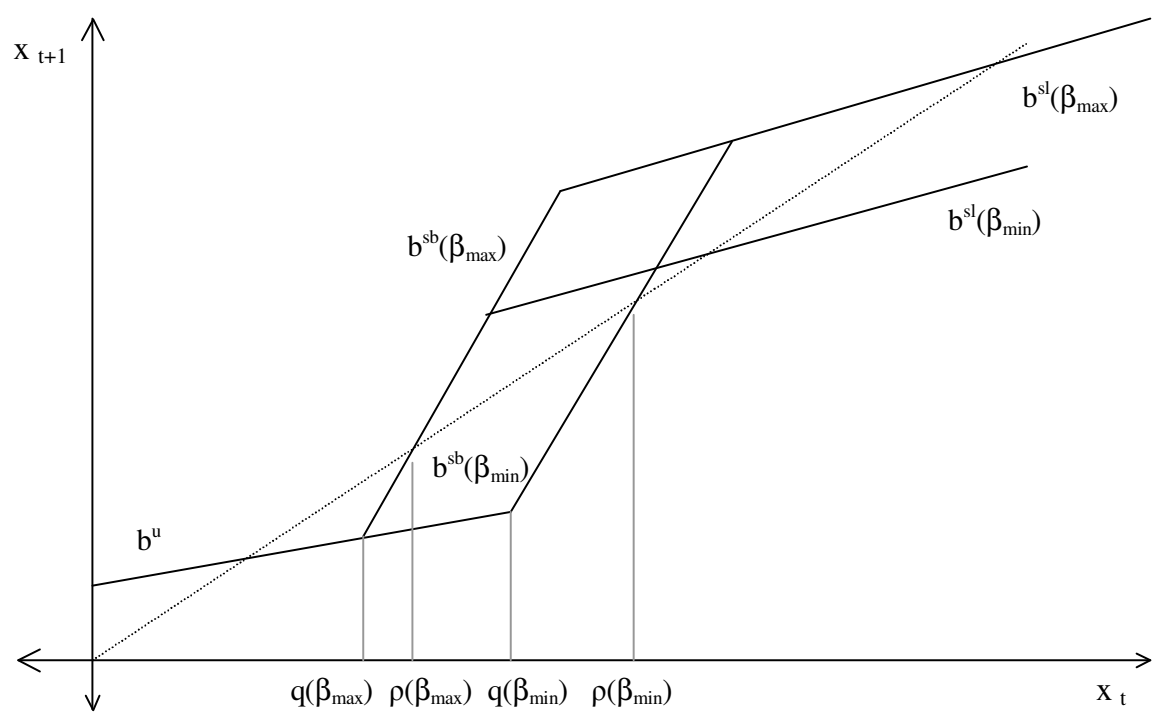

Figure 1: Division Values of Wealth

Note that $b^{u}$ and $b^{s l}$ have the same slope (in function of $x$ ) and that at the same time, according to assumption 2, the latter is smaller than that from $b^{s b}$. These aspects will be made clearer by observing Figure 1.

The figure shows the limit values that $q$ can take in relation to the values of $\beta$. It is also seen there that the higher $\beta$ is, the lower the level of initial wealth the agents should have in order to decide whether to study or not- it will be more profitable. In that sense, it is clearly seen that it is more likely that a person invests in human capital when his or her parent's income (from which inheritance is just a proportion) increases as well as when the ability / tendency to work is higher.

\subsection{Steady State}

In order to find the steady state, in the first place it is necessary to note that there will be an initial value of wealth as from which -for higher values- all future generations will remain skilled. According to this value, it will be possible to know the limit distribution of wealth and incomes through the initial distributions of $x$ and $\beta$. Such as it can be seen from Figure 1, it is necessary to do $x_{t+1}=x_{t}$ in the function $b^{s b}\left(x_{t}\right)$ in order to find that value. 
Lemma 2 There is a point $\rho$ for each agent

$$
\rho(\beta)=\frac{(1-\alpha)\left[h(1+i)-w_{s} \beta\right]}{(1-\alpha)(1+i)-1},
$$

so that if in any period $t, x_{t}<\rho\left(x_{t}>\rho\right)$ for the member of any dynasty, so in the limit the future generations from this dynasty will be unskilled (skilled).

Apart from a value of initial wealth (in function of $\beta$ ) that enables identification of what proportion of people qualify, the levels of steady state can be found. In accordance with the assumptions, there will be a level of initial wealth in a steady state which is the same for all unskilled workers. As can be seen in Figure 2, this derives from $x_{t+1}=x_{t}$ in the function $b^{u}\left(x_{t}\right)$.

Lemma 3 The level of wealth $(x)$ of steady state for those agents with $x_{0}<\rho$ will be:

$$
x_{s s}^{u}=\frac{(1-\alpha) w_{u}(2+r)}{1-(1-\alpha)(1+r)} .
$$

Likewise, the value of initial wealth in steady state for skilled workers is also likely to be found. However, in this case it will not be a unique value since it will differ in relation to $\beta$ in each dynasty.

Lemma 4 Wealth levels $(x)$ at a steady state for those agents with $x_{0}>\rho$ will be:

$$
x_{s s}^{s l}(\beta)=\frac{(1-\alpha)\left[w_{s} \beta-h(1+r)\right]}{1-(1-\alpha)(1+r)} .
$$

In accordance with the previous lemmas and Figure 2, wealth distribution under steady states $(s s)$ will be likely to be found. It must be observed that a proportion of the agents (specifically those who have $x_{0}<\rho(\beta)$ ) will be poor unskilled with a level of wealth $x_{s s}^{u}$, whereas the rest of the population (those who have had $x_{0}>$ $\rho(\beta)$ ) will have incomes around some value (depending their $\beta$ ) within the interval $\left[x_{s s}^{s l}\left(\beta_{\min }\right), x_{s s}^{s l}\left(\beta_{\max }\right)\right] .{ }^{12}$ Thus, the function of density of distribution at steady state could be written only as a function of parameters.

\footnotetext{
${ }^{12}$ Note that according to assumption 1 it is verified that $x_{s s}^{u}<x_{s s}^{s}\left(\beta_{\min }\right)$.
} 


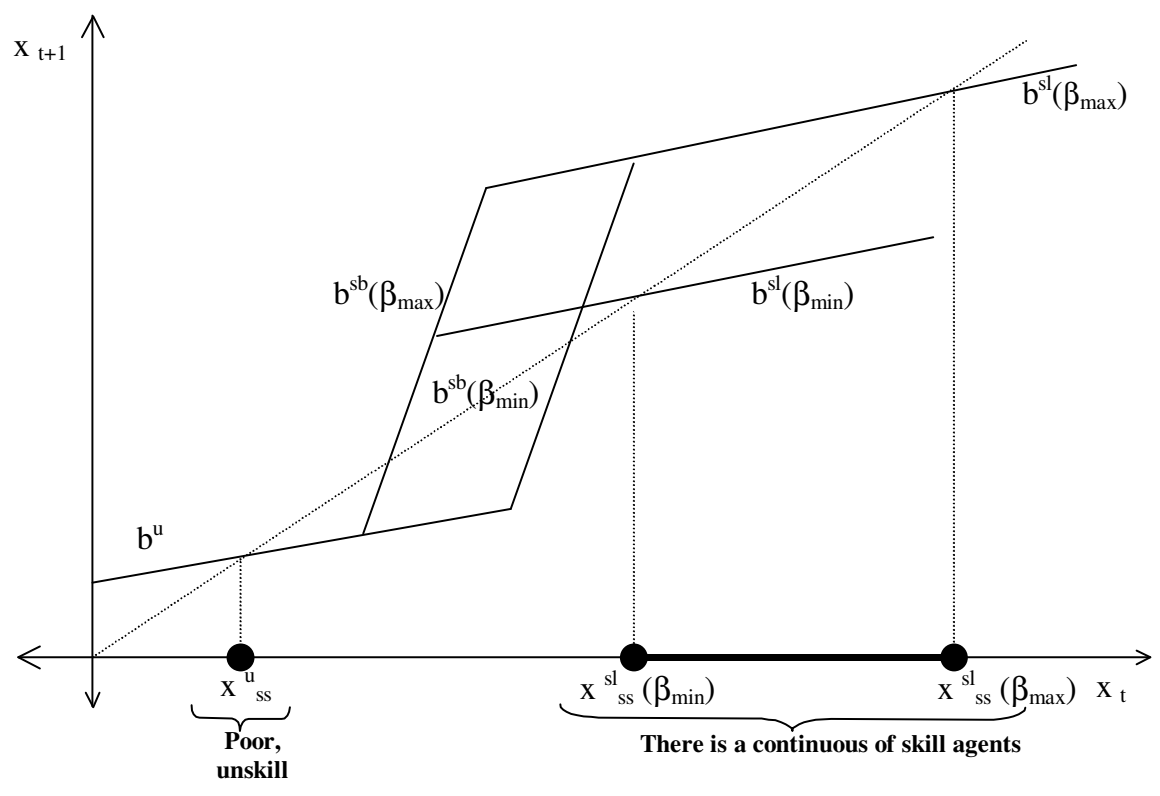

Figure 2: Limit distribution of wealth

\section{Alternative Solutions}

Once the structure has been expounded and the basic case solved (from now onwards called total fee) it is possible to find the solutions to the model under different financing schemes for the investment in human capital: uniform taxation and graduates taxation. ${ }^{13}$ In both cases, we are exogenously introducing the government in this economy. The idea here is to see what happen if the government plays a role in human capital accumulation (as actually it does in most of the countries). We are not interested in analyze why the government decide to participate.

What the different schemes analyzed in the section have in common is that a subsidy $(s)$ is granted and it is financed with debt taken by the government at the interest rate $i_{g}$ which is subsequently paid by taxing adults. Even though this will be later discussed more deeply, it is worth pointing out that the assumption will be that $i \geq i_{g}>r$.

We now introduce an assumption that, in some way, set an upper bound for the government interest rate. This will hold just when specifically recalled.

Assumption 3: $\beta_{\min } w_{s}>\left(1+i_{g}\right) h$.

\footnotetext{
${ }^{13}$ Another system to investigate would be 'picking the winners'. However, the interest in this policy is reduced if the problems of implementability of this system are considered. As Lucas (1988) stated 'In the model, picking the winners is easy. If only it were so in reality!'.
} 
In addition, it is assumed that the subsidy is not total ${ }^{14}$, so that the cost the agents face when deciding whether to study or not is said to be $(1-s) h$. The fact that the amount of the subsidy can be charged during the following period allows for no alteration in intergenerational equity. Thus, the generation that enjoys and makes profits from the subsidy is the same that finances it.

The government fixes the tax rate $(\tau)$ over the tax base $\left(I_{t}\right)$ so as to comply with the following budget constrains:

$$
\begin{aligned}
h s P_{t} & =\frac{B_{t+1}}{1+i_{g}} \\
B_{t} & =\tau_{t} I_{t},
\end{aligned}
$$

where $B_{t}$ is the indebtedness taken in $t-1$ at the rate $i_{g}$, due in $t$ and $P_{t}$ the proportion of agents that decide to qualify during $t$. Thus, it can be written,

$$
\tau_{t}=\frac{\left(1+i_{g}\right) h s P_{t-1}}{I_{t}}
$$

Since for both the taxation for graduates and the taxation for all the population, the tax base $\left(I_{t}\right)$ depend on how many and who of the agents study and, in order to answer these two questions it is necessary to know the tax rate $\left(\tau_{t}\right)$, the $\tau_{t}$ of equilibrium $\left(\tau_{t}^{*}\right)$ must be defined carefully:

Definition $4 \tau_{t}$ of equilibrium is $\tau_{t}^{*}$ for which if the agents take $\tau_{t}^{*}$ as given and decide consequently (determine $I_{t}$ ), it is verified that if the government applies $\tau_{t}^{*}$ the budget restrictions will be satisfied.

In the different cases that follow several alternatives are presented over $I_{t}$ and the solutions are subsequently found.

\subsection{Uniform taxes}

An alternative for financing higher education is to obtain resources from applying a uniform rate over the incomes of all the adult generation. Consequently, since taxes are charged with uniform rate $(\tau)$ to all adults, the budget restrictions of the government during the period $t$ will be:

$$
B_{t}=\tau_{t}\left[w_{s} \widehat{\beta}_{t-1} P_{t-1}+w_{u}\left(1-P_{t-1}\right)\right]
$$

\footnotetext{
${ }^{14}$ If $s=1$, the subsidy is total and according to the assumption 1 all agents will choose to study.
} 


$$
h s P_{t}=\frac{B_{t+1}}{1+i_{g}}
$$

where $\widehat{\beta}_{t}$ is the value of the mean of $\beta$ of those who qualify during the period $t .^{15}$ From then onwards, it can be said that the taxation rate will depend on the number of students, as follows,

$$
\tau_{t}^{u}=\frac{\left(1+i_{g}\right) h s P_{t-1}}{\left[w_{s} \widehat{\beta}_{t-1} P_{t-1}+w_{u}\left(1-P_{t-1}\right)\right]} .
$$

It can be seen here that the values of $q_{t}$ are modified

Lemma 5 Under a system of partial subsidy and uniform taxes, it can be seen that

$$
q_{t}^{u}(\beta)=\frac{w_{u}\left(2+r-\tau_{t}^{u}\right)+h(1-s)(1+i)-w_{s} \beta\left(1-\tau_{t}^{u}\right)}{i-r} .
$$

At the same time, the steady state can be characterized under this alternative, as from the values of $\rho^{u}$ and $x_{s s}$.

Lemma 6 Under a system of partial subsidy and uniform taxes, the values that characterize the steady state will be

$$
\begin{gathered}
\rho^{u}(\beta)=\frac{(1-\alpha)\left[h(1-s)(1+i)-w_{s} \beta\left(1-\tau^{u}\right)\right]}{(1+i)(1-\alpha)-1} \\
x_{s s}^{u, u}=\frac{(1-\alpha)\left(2+r-\tau^{u}\right) w_{u}}{1-(1-\alpha)(1+r)} \\
x_{s s}^{s l, u}(\beta)=\frac{(1-\alpha)\left[w_{s} \beta\left(1-\tau^{u}\right)-h(1-s)(1+r)\right]}{1-(1-\alpha)(1+r)} .
\end{gathered}
$$

\subsection{Graduates' taxes}

As an alternative to the previous systems, it is possible to analyze another one where those who pay in order to finance the University are the same people who attend it. Here, it can be stated that:

$$
\begin{gathered}
B_{t}=\tau_{t} w_{s} \widehat{\beta}_{t-1}^{g} P_{t-1} \\
h s P_{t}=\frac{B_{t+1}}{1+i_{g}},
\end{gathered}
$$

\footnotetext{
${ }^{15}$ Note that even $\beta$ and $x$ are independent at time zero, the mean of $\beta$ those agents who study is higher than the total mean of $\beta$ (that is to say $E[\beta \| x>\rho(\beta)]>E[\beta]$ ).
} 
where $\widehat{\beta}_{t}^{g}$ is the value of the mean of $\beta$ of those who qualify during the period $t$ in this system. From there, it can be obtained that

$$
\tau_{t}^{g}=\frac{\left(1+i_{g}\right) h s}{w_{s} \widehat{\beta}_{t-1}^{g}} .
$$

In this case, it is also possible to find how the values of $q_{t}$ are modified

Lemma 7 Under a system of partial subsidy and graduates' taxes, it can be proved that

$$
q_{t}^{g}(\beta)=\frac{w_{u}(2+r)+h(1-s)(1+i)-w_{s} \beta\left(1-\tau_{t}^{g}\right)}{i-r}
$$

Now, in order to finish the characterization of the solution to this scheme, the sole calculation of the values of $\rho^{g}$ and $x_{s s}$ remains.

Lemma 8 Under a system of partial subsidy and graduates' taxes, the values characterizing the steady state will be

$$
\begin{gathered}
\rho^{g}(\beta)=\frac{(1-\alpha)\left[h(1-s)(1+i)-w_{s} \beta\left(1-\tau^{g}\right)\right]}{(1+i)(1-\alpha)-1} \\
x_{s s}^{u, g}=\frac{(1-\alpha)(2+r) w_{u}}{1-(1-\alpha)(1+r)} \\
x_{s s}^{s l, g}(\beta)=\frac{(1-\alpha)\left[w_{s} \beta\left(1-\tau^{g}\right)-h(1-s)(1+r)\right]}{1-(1-\alpha)(1+r)} .
\end{gathered}
$$

\section{Evaluation of alternatives}

The alternatives of financing human capital presented in the previous sections will be compared in this section. Such comparison will mainly be made in two ways. In the first place, certain endogenous variables are evaluated in the steady state, which allows to characterize the solution. Then, the solution to the model for each period is to be found according to a set of parameters that are previously determined. In this last exercise, the distribution of wealth of each generation is obtained. Thus, the alternatives will be able to be compared according to various welfare indicators. 


\subsection{In the steady state}

The comparison of alternatives for financing human capital investment in the steady state does not allow, in most cases, to obtain results free from ambiguities. However, it is highly useful to know on what grounds one alternative is better than the other and when one is better than the other free of parameters specification.

The properties of the endogenous variables $\left[\rho, x^{s}, x^{u}\right]$ allow for the characterization of wealth distribution in the steady state.

Notwithstanding, before starting, it is possible to plan an innocuous assumption that simplifies the comparison in algebraic terms. In that sense, it is supposed that the initial wealth distribution is such that there exists a proportion of people below and above $\rho$ for the three systems.

Assumption 4: $\int_{0}^{\rho^{i}} f_{t}(x) d x>0$ and besides $\int_{\rho^{i}}^{\infty} f_{t}(x) d x>0$ for $i=a, g, u$.

\subsubsection{Comparison of alternatives according to $\rho$}

This is the most difficult comparison due to the fact that $\rho$ is a value of $x$ which is a function of $\beta$.

Proposition 1 There will be a greater proportion (amount) of poor people in the system of graduates' taxation compared to the system of uniform taxation. That is

$$
\rho^{g}(\beta)>\rho^{u}(\beta) \forall \beta \text { in the interval }\left[\beta_{\min }, \beta_{\max }\right] .
$$

As a result of comparing 'the proportion that decide to study' between the graduates taxation and uniform taxation systems, it is found that will be higher under the system of uniform taxation. Such result is very intuitive, as in this case the cost of contracting a debt is the same $\left(i_{g}\right)$, consequently, the fact that those who do not study pay part of the education cost within the system of uniform taxation, reduces its cost.

Proposition 2 If the assumption 3 is satisfied, there will exist a greater proportion (amount) of poor people in the fees system compared to the system of graduates' taxes. That is

$$
\rho^{a}(\beta)>\rho^{g}(\beta) \forall \beta \text { in the interval }\left[\beta_{\min }, \beta_{\max }\right] .
$$

If assumption 3 holds, it is found that 'the proportion that decides to study' will be higher in the systems of taxation compared to the fees system. This result is intuitive if it is considered that the rate at which those who are on the verge of when deciding whether to study or not are indebted to, is higher in the case of total feeing. 
Conclusion 1 The previous propositions indicate that the system of uniform taxation maximizes the proportion (amount) of students.

\subsubsection{Comparison of alternatives according to $x_{s s}^{u}$}

The wealth value of those who decide not to study will be the same in the cases of graduates fees and taxations, and less in the case of uniform taxation. The explanation is very simple: the last is the unique system in which they have to pay taxes.

Proposition 3 It is possible to demonstrate that $x_{s s}^{u, g}=x_{s s}^{u, a}>x_{s s}^{u, u}$.

Conclusion 2 Together with the previous conclusion, it is possible to mention that even though in the system of uniform taxation fewer poor people are found, those who remain in this situation are poorer (their income after taxes is lower).

\subsubsection{Comparison of alternatives according to $x_{s s}^{s l}$}

The wealth level of those qualified will differ between the several systems according to the value of some parameters. The comparison of the different values of $x_{s s}^{s l}$ is made considering a value of $\beta$ as given, which will be supposed, in most cases by simplicity equal to the mean of the agents that decide to study under the system of uniform taxation $(\widehat{\beta}) \cdot{ }^{16}$

In the first place, it is observed that the wealth level of the qualified in the steady level will be higher in the scheme of uniform taxation than in the system of graduates' taxation, provided there exists unskilled (who will pay part of the cost of receiving education under the system of uniform taxation).

Proposition 4 The wealth of the steady state of the qualified is higher under the system of uniform taxation than in the system of graduates' taxation $x_{s s}^{s l, u}(\widehat{\beta})>x_{s s}^{s, g}(\widehat{\beta})$.

In turn, wealth of steady state of the qualified will be higher under the feeing system than in the system of graduates taxation. ${ }^{17}$

\footnotetext{
${ }^{16}$ Note that if $x_{s s}^{s l}$ under a given system (for example $x_{s s}^{s l, A}$ ) is higher than $x_{s s}^{c}$ under another system (for example $x_{s s}^{c, B}$ ) with a given value of $\beta$ (for example $\beta^{*}$ ), that is $x_{s s}^{c, A}\left(\beta^{*}\right)>x_{s s}^{c, B}\left(\beta^{*}\right)$ so, it is confirmed that $x_{s s}^{c, A}(\beta)>x_{s s}^{c, B}(\beta)$ for all $\beta$.

${ }^{17}$ In this case, for the sake of simplicity, the comparison for $\beta$ given is made in the level of the mean of those who study in the system of graduates taxation.
} 
Proposition 5 It is confirmed that the wealth of the steady state of those qualified is higher under the feeing system than in the system of graduates taxation $\left(x_{s s}^{s l, a}(\widehat{\beta})>x_{s s}^{s l, g}(\widehat{\beta})\right)$.

Finally, it is possible to compare wealth in steady state of those qualified in the feeing and uniform taxation systems. In this case, we find that wealth in the feeing system will be higher than in the system of uniform taxation only when

$$
\left(1+i_{g}\right) A>(1+r),
$$

where $A=\frac{w_{s} \widehat{\beta} P_{s s}^{u}}{w_{u}\left(1-P_{s s}^{u}\right)+w_{s} \beta P_{s s}^{u}}$ is the proportion of the cost of education that graduates pay in the system of uniform taxation.

\subsection{Using numerical examples}

Considering that the equations describing the system dynamics are non-linear, it is not possible to apply a major analytical characterization. Consequently, numerical examples are used in this section to compare the solutions in the different systems.

In order to obtain the results in terms of numbers, values for the model parameters and for certain variables in $t=0$ have to be established. In Table 1 the determined values are introduced, with which the results presented afterwards are obtained. 
Table 1: Values for simulation

\begin{tabular}{|c|c|c|}
\hline Variables & Case 1 & Case 2 \\
\hline$\beta:$ Ability-Effort & $\log N(1.16,0.19)$ & $\log N(1.16,0.19)$ \\
\hline$x_{0}:$ Initial wealth & $U(4.1,2.3)$ & $U(4.1,2.3)$ \\
\hline$s:$ Proportion subsidized & $30 \%$ & $30 \%$ \\
\hline$h:$ Cost of education & 5.5 & 5.5 \\
\hline$r$ : Passive interest rate & $12 \%$ & $12 \%$ \\
\hline$i$ : Private cost for financing HK & $180 \%$ & $180 \%$ \\
\hline$i_{g}:$ Public Cost for financing HK & $144 \%$ & $54 \%$ \\
\hline$w_{u}$ : Salary of the non-qualified & 1 & 1 \\
\hline$w_{s}$ : Salary of the qualified & 9 & 9 \\
\hline$\alpha$ : Proportion of inheritance & $50 \%$ & $50 \%$ \\
\hline
\end{tabular}

Distribution of $\beta$ is assumed to be log normal, in order to allow that very few of them have extremely high values. Initial wealth $\left(x_{0}\right)$ is supposed to have a uniform distribution even knowing that in the different economies it usually resembles a lognormal. This last thing is justified because we pretend to start the analysis from a situation where 'the forces of the market' have not yet acted to distribute wealth.

The value of $s$ is deliberately chosen to be small enough to reflect a system in which the government is only in charge of the direct costs (running a university).

The values for the active interest rates, both for the government and the private sector, should be further discussed. First, the interest rate for the private sector is set 'sufficiently high' to finance investment in human capital, since it is believed that this is what is usually observed in the economies, revealing both the lack of incentive to pay the debt once the investment has been done and the impossibility to grant guarantees.

Taking into account the rate that the government is charged with to finance the investment in human capital, two values were established. In principle, there are not enough reasons to justify that the public sector can perform such task better than the private sector. This argument is even stronger in developing countries, where the institutional structure of the government is usually considerably weak (the financial market is in fact closed for some developing countries). Although it is believed that the latter scenario would be the closest to reality, it was set that $i_{g}=0.3 i$ to observe what happens if the governments achieve this task much better than the private sector.

The values of salaries, the passive interest rate and the cost of education were established at presumably reasonable values. Moreover, what was being sought with 
these values was that the proportion of students under the uniform system were close to what currently happens in Argentina (especially in the case where $i_{g}=144 \%$ ).

Once parameters values and the initial distribution of variables are established, it is possible to compute economies under the different systems. In this case, it was supposed that the economy comprises 5000 agents, who leave different inheritances to their children according to the economy decision of investing in human capital. This economy is computed from $t=0$ to $t=35$, where it can already be observed that the values of the variables become stabilized.

Next, there is a presentation of the results arising from comparing the distributions of each generation in terms of inequality, poverty, wealth as well as average utility and welfare.

\subsubsection{Inequality}

It is usual in economics to consider inequality of income or of individual welfare as an indicator of society's welfare. In this case, the resulting inequality between the different schemes is measured according to the most used indicators for this task: Gini's coefficient and Atkinson's index with parameters of aversion to inequality equal to 1 and 2 .

The results, presented in Appendix B, show that according to inequality, the system of taxes imposed to the graduate is the best, and the one of uniform taxation is the worst.

Conclusion 3 The distribution of income resulting from the system of uniform taxation is the most unequal, followed by the system of total feeing and finally by the one of graduates' taxation.

This result originates from the fact that in the system of uniform taxation, the poor will finance part of the education of the wealthy. Furthermore, the system of graduates taxation is better in terms of equality than the feeing system, because, even though the poor are always in the same condition, the wealthy are less wealthy, because they pay a portion of their education with an interest rate higher than $r$ (in both cases).

\subsubsection{Poverty}

Another concept that is usually related to the welfare of a society is poverty. The proportion of poor people and the poverty depth are usually two topics of concern for those in charge of designing economic policy. 
In this case, measurements are made by means of three indicators: the incidence rate (which measures the proportion of poor people), the poverty gap (which also considers the amount of income left to come out of poverty) and Foster, Greer and Thorbecke's index (1984) (referred to as FGT) with $\alpha=2$ (which increasingly considers the poverty gap).

The poverty line has been defined with an intermediate value between $\left[x_{s s}^{u}, x_{s s}^{s}\left(\beta_{\min }\right)\right]$. Consequently, the incidence rate also indicates the proportion of agents that do not qualify.

The results found, which are presented in the appendix, change according to the indicator used. When only the amount of poor people is considered, the system of uniform taxation is the best (as we expected from the steady state analysis). However, when there is increasing overvaluation of the poverty gap in the case where $i_{g}$ is similar to $i$, such system is the worst. In turn, when considering $i_{g}=54 \%$, the feeing system is the worst.

Conclusion 4 The lowest proportion of poor people is achieved with the system of uniform taxation, which means that this system maximizes the amount of students. However, when the depth of poverty is being considered (FGT with $\alpha=2$ ) in the case with the most reasonable parameter values, the system of uniform taxation is the worst.

As noticed in proposition 3, the system of uniform taxation is the one from which results the lowest wealth for the poor. However, as it derives from proposition 1, in such system the proportion of poor people will be lower. Thus, the incidence rate is lower in the uniform taxation system, but when poverty depth is considered that system is worse than the others.

\subsubsection{Wealth and utility average}

A generalized manner to evaluate the performance of an economy is through its per capita income. In this case, results are obtained from the wealth and utility means.

The findings obtained using wealth average allow to conclude that according to this measurement of welfare, the best system is that of total feeing in the case where $i$ is similar to $i_{g}$, while the system of uniform taxation is better when this difference is made larger. In turn, it can be clearly observed when the mean utility of economy is being considered, that the system of uniform taxation is the less beneficial (except when $i_{g}=54 \%$ ). 
Conclusion 5 The average wealth is higher in the feeing system, while according to utility the system of uniform taxation is the worst (except when $i_{g}=54 \%$ ).

These results arise from considering the difference between $i_{g}$ and $r$, which are the reference rates for the wealthy. When this difference is very significant, the feeing system is the best; while when they are similar, the fact that in the system of uniform taxation the amount of students is higher improves the average wealth level of this system. In turn, this system is the worst in terms of utility since the poor are poorer, which is considerably reflected in terms of utility as the function is concave.

\subsubsection{Welfare}

A frequent way of evaluating an economy is through a function of social welfare in the Bergson-Samuelson way $(W)$, which adds the individual levels of life.

$$
W=W\left(U_{1}, U_{2}, \ldots U_{N}\right)
$$

As Gasparini and Sosa Escudero (2001) mentioned, these functions are useful as an instrument at the disposal of the analyst or the policy maker to evaluate the global welfare of an economy. Since this exercise necessarily implies the addition of levels of individual lives, function $W$ proposes an ordered and consistent way of doing this exercise.

A function that turns out to be considerably useful and used is the Atkinson basic principles.

$$
\begin{gathered}
W_{a}(\varepsilon)=\left(\frac{1}{N} \sum_{i=1}^{N} \frac{Y_{i}^{1-\varepsilon}}{1-\varepsilon}\right)^{1-\varepsilon} \text { for } \varepsilon \geq 0, \varepsilon \neq 0 \\
W_{a}(\varepsilon=0) \text { is replaced by } \ln W_{a}=\frac{1}{N} \sum_{i=1}^{N} \ln y_{i},
\end{gathered}
$$

where parameter $\varepsilon$ is defined as a measurement of aversion to inequality. Based on this definition, a Rawlsian welfare function can be found when $\varepsilon=\infty$, an utilitarian or in the Bentham's way when $\varepsilon=0$ and the following function summarized in the mean and Atkinson's inequality index when $\varepsilon=1,2$.

$$
W_{a}(\varepsilon)=\mu(1-A(\varepsilon)) \text { with } \varepsilon=1,2,
$$

where $\mu$ is the mean of distribution and $A(\varepsilon)$ is Atkinson's inequality index with aversion to inequality $\varepsilon$. 
The results are presented in the appendix according to these four definitions of welfare (utilitaran, rawlsian, Atkinson $\varepsilon=1$ and $\varepsilon=2$ ), together with two functions defined according to the mean and the Gini by Sen and Kakwani, respectively

$$
\begin{gathered}
W_{s}=\mu(1-G) \\
W_{k}=\frac{\mu}{1+G},
\end{gathered}
$$

where $\mathrm{G}$ is Gini's inequality index.

From comparing the different systems according to the different representations of society's welfare, it comes out that in all the cases the feeing or graduates' taxation systems are better than the system of uniform taxation. While in the cases where $i$ is similar to $i_{g}$ the system of uniform taxation is clearly the worst; in the case where $i_{g}=54 \%$ it is found to be in an intermediate position after the system of graduates taxation. The latter is the one which appears most frequently as the best system.

Conclusion 6 In terms of welfare, all functions indicate that the system of uniform taxation is worse than the feeing or graduates taxation systems. Between the other two, most of the functions show that the system of graduates taxation is the best.

These results, when jointly considering inequality and the level of utility, provide their own explanations. Since the system of graduates taxation is the best in most cases in terms of inequality, and the utility average level resulting from establishing this system is also the best or similar to it, when speaking in terms of welfare it frequently appears as the most beneficial for society.

\section{Discussion of the basic assumptions}

The results previously presented are as valid and convincing as the model from which they are derived. This is relevant for comparing the model with other ways of explaining the financing of investment in human capital and besides, for considering the discrepancies between the model and the real economy.

Regarding other alternatives to explain the financing of investment in human capital, there are in the literature a large number of structures, among which, those used by Glomm and Ravikumar (1992) and Caucutt and Kumar (2000) have been previously highlighted. The proposals evaluated here have not yet been analyzed in either work, and their development would be significantly useful in order to compare the results. 
At least three remarkable discrepancies exist between the real economy and the model presented here. In the first place, it has been supposed that the non-qualified salaries do not differ in their abilities, which does not occur in the real economy. This assumption is also in Galor and Zeira (1993).

In the second place, it has been supposed that there is no uncertainty as to whether students will end their university course of studies or not. This fact could be interesting to introduce but this change is not minor and this is left for future research.

Third, it was assumed that there is not uncertainty respect to the ability, which is perfectly transmitted from parents to children. Acemoglu (2001) and Romero (2004) also have this assumption.

Also, we assumed by simplicity that there are not external benefits of education. To include externalities could affect our results since a greater number of students will affect the utility of those who are not studying. Nevertheless, our conjecture is that the externalities should be very important to change the quantitative results. Also, the no externalities assumption in order to isolate the impact of financial frictions on the human capital decision.

Even though it is possible to conjecture that such modifications will not change the main results, advancing in both directions will surely contribute to study the alternatives of university financing proposed. Notwithstanding, as far as there is no model development or sound theoretical explanations in order to approach the evaluation of alternatives of university financing from which different results will be obtained, the conclusions found are considered to be worthy.

\section{Comments for Argentina}

Taking into consideration the system of uniform taxation as a simplification of a system like the Argentinean, where the funds derive from a relatively uniform taxation system according to income levels ${ }^{18}$, it is possible to find some conclusions to debate the alternatives of university financing in Argentina.

The results from the comparison allow us to conclude that in those scenarios closest to the reality of the model previously presented, the system of taxes to graduates is the best in terms of welfare. In turn, it has been found that a system of financing

\footnotetext{
${ }^{18}$ Gasparini (1998) shows that the Argentinean taxation system is relatively uniform with respect to the current income.
} 
with a uniform tax is worse than the system of graduates taxation, in terms of inequality, poverty (considering its intensity) and average utility. In that sense, the only justification to maintain a system of uniform taxation seems to be that it maximizes the amount of students that attend university. These findings are in some way related to the idea previously presented '.. . the rest of the universities -mass universities- are no more than a camouflage of unemployment'.

A political economy analysis is needed to understand the obstacles associated to a reform. This could be an interesting issue for future research. At this point, we can just do the following conjecture. Generally, the students nearest to the limit between to study or not (because their abilities, tendency to effort and income) are the ones who have more influence in the university political parties. From our model, their position against any reform of the system financing the Universities is a rational decision, because in another system they could not be student. The unskilled group is the one who should support any reform (from uniform taxation to total fee or taxes to graduated individuals). However, usually they are not taken into account in the discussion of what financing system is preferred. Finally, the model predicts logic behavior for the group of skill lenders. Contrary to the unskilled, this group will prefer a reform only to the feeing system (because in the system of taxes to graduated they have to pay the interest rate of the government $i_{g}>r$ ). As they are better in the status quo than under a graduate taxation system, their interest to the reform is not so strong.

In Argentina, the reform should be introduced by a Law of the National Congress, which represents to all the individuals in the country. Thus, since in Argentina the group of unskilled agents are clearly the majority, a reform in which improves inequality, poverty (considering its intensity) and average utility, could be done, if the issue is put to the vote and this group (or their legislators) votes rationally. 


\section{Appendix A}

\subsection{Proof of Lemma 1}

Proof. According to assumption 1 we know that $\beta_{\min } w_{s} \geq h(1+r)+w_{u}(2+r)$, consequently those who have $x_{t} \geq h$ will prefer to invest in human capital (independently from $\beta_{i}$ ). Thus, in order to find the level of initial wealth from which agents choose to receive education, we have to compare $U^{s b}$ and $U^{u}$ to find the level of $x$ for which it is verified that $U^{s b} \geq U^{u}$. Considering that the less the proportion of resources for education that are not their own funds the less income-producing deciding to study turns out to be, the minimum $x$ level for which studying is more beneficial in terms of utility will be found

$$
\begin{gathered}
U^{s b}=\ln \left[w_{s} \beta+(x-h)(1+i)\right]+\varepsilon \geq U^{u}=\ln \left[\left(x_{t}+w_{u}\right)(1+r)+w_{u}\right]+\varepsilon \\
\ln \left[w_{s} \beta+(x-h)(1+i)\right]+\varepsilon \geq \ln \left[\left(x_{t}+w_{u}\right)(1+r)+w_{u}\right]+\varepsilon \\
\ln \left[w_{s} \beta+(x-h)(1+i)\right] \geq \ln \left[\left(x_{t}+w_{u}\right)(1+r)+w_{u}\right] \\
w_{s} \beta+(x-h)(1+i) \geq\left(x+w_{u}\right)(1+r)+w_{u} \\
w_{s} \beta-w_{u}-w_{u}(1+r)-h(1+i) \geq x(1+r)-x(1+i) \\
w_{s} \beta-w_{u}(2+r)-h(1+i) \geq x(r-i) \\
x(i-r) \geq w_{u}(2+r)+h(1+i)-w_{s} \beta \\
q(\beta) \geq \frac{\left[w_{u}(2+r)+h(1+i)-w_{s} \beta\right]}{(i-r)} .
\end{gathered}
$$

\subsection{Proof of Lemma 2}

Proof. In the first place we have to assume that $(1-\alpha)(1+r)<1<(1-\alpha)(1+i)$. Then, from the equations that reflect the dynamics of wealth, it is possible to pose the following equations

$$
\begin{gathered}
x_{t+1}^{u}=(1-\alpha)(1+r) x_{t}+w_{u}(2+r)(1-\alpha) \quad \text { if } \quad x_{t}<q(\beta) \\
x_{t+1}^{s b}=(1-\alpha)(1+i) x_{t}+(1-\alpha)\left[w_{s} \beta-h(1+i)\right] \quad \text { if } q(\beta) \leq x_{t}<h \\
x_{t+1}^{s l}=(1-\alpha)(1+r) x_{t}+(1-\alpha)\left[w_{s} \beta-h(1+r)\right] \quad \text { if } h \leq x_{t}
\end{gathered} .
$$

We will notice that it is possible to find point $\rho_{i}$ since it is the value/where the following takes place

$$
b^{s b}\left(x_{t}\right)=x_{t}
$$




$$
\begin{gathered}
(1-\alpha)\left[w_{s} \beta+\left(x_{t}-h\right)(1+i)\right]=x_{t} \\
(1-\alpha)\left[w_{s} \beta+\left(x_{t}-h\right)(1+i)\right]=x_{t} \\
(1-\alpha) w_{s} \beta+(1-\alpha)\left(x_{t}-h\right)(1+i)=x_{t} \\
(1-\alpha) x_{t}(1+i)-x_{t}=h(1+i)(1-\alpha)-(1-\alpha) w_{s} \beta \\
x_{t}[(1-\alpha)(1+i)-1]=(1-\alpha)\left[h(1+i)-w_{s} \beta\right] \\
\rho(\beta)=x_{t}=\frac{(1-\alpha)\left[h(1+i)-w_{s} \beta\right]}{[(1-\alpha)(1+i)-1]} .
\end{gathered}
$$

\subsection{Proof of Lemma 3}

Proof. These values are derived from levelling the /inheritance functions with the initial wealth level. For $x_{u}$ this is

$$
\begin{gathered}
b_{u}\left(x_{t}\right)=x_{t} \\
(1-\alpha)\left[\left(x_{t}+w_{u}\right)(1+r)+w_{u}\right]=x_{t} \\
(1-\alpha)\left(x_{t}+w_{u}\right)(1+r)+(1-\alpha) w_{u}=x_{t} \\
(1-\alpha) x_{t}(1+r)+(1-\alpha) w_{u}(1+r)+(1-\alpha) w_{u}=x_{t} \\
(1-\alpha) w_{u}(1+r)+(1-\alpha) w_{u}=x_{t}-(1-\alpha) x_{t}(1+r) \\
(1-\alpha)(2+r) w_{u}=x_{t}[1-(1-\alpha)(1+r)] \\
x_{s s}^{u}=\frac{(1-\alpha)(2+r) w_{u}}{[1-(1-\alpha)(1+r)]}
\end{gathered}
$$

Note that $x_{u}$ is not a function of $\beta$.

\subsection{Proof of Lemma 4}

Proof. According to figure 2 the following has to be levelled

$$
\begin{gathered}
b^{s l}\left(x_{t}\right)=x_{t} \\
(1-\alpha)\left[w_{s} \beta+\left(x_{t}-h\right)(1+r)\right]=x_{t} \\
(1-\alpha) w_{s} \beta+(1-\alpha) x_{t}(1+r)-h(1-\alpha)(1+r)=x_{t} \\
(1-\alpha) w_{s} \beta-h(1-\alpha)(1+r)=x_{t}-(1-\alpha) x_{t}(1+r) \\
(1-\alpha)\left[w_{s} \beta-h(1+r)\right]=x_{t}[1-(1-\alpha)(1+r)] \\
x_{s s}^{s l}(\beta)=\frac{(1-\alpha)\left[w_{s} \beta-h(1+r)\right]}{[1-(1-\alpha)(1+r)]} .
\end{gathered}
$$




\subsection{Proof of Lemma 5}

Proof. In order to find the value of $q_{t}$ the following has to be done,

$$
\begin{gathered}
U^{s b}=\ln \left[w_{s} \beta\left(1-\tau_{t}^{u}\right)+(x-h(1-s))(1+i)\right]+\varepsilon=U^{u}=\ln \left[\left(x+w_{u}\right)(1+r)+w_{u}\left(1-\tau_{t}^{u}\right)\right]+\varepsilon \\
w_{s} \beta\left(1-\tau_{t}^{u}\right)+(x-h(1-s))(1+i)=\left(x+w_{u}\right)(1+r)+w_{u}\left(1-\tau_{t}^{u}\right) \\
x(i-r)=w_{u}\left(2+r-\tau_{t}^{u}\right)+h(1-s)(1+i)-w_{s} \beta\left(1-\tau_{t}^{u}\right) \\
q_{t}^{u}(\beta)=\frac{w_{u}\left(2+r-\tau_{t}^{u}\right)+h(1-s)(1+i)-w_{s} \beta\left(1-\tau_{t}^{u}\right)}{i-r} .
\end{gathered}
$$

\subsection{Proof of Lemma 6}

Proof. In order to obtain $\rho$ the following has to be done

$$
\begin{gathered}
x=(1-\alpha)\left[w_{s} \beta\left(1-\tau^{u}\right)+(x-h(1-s))(1+i)\right] \\
x-x(1+i)(1-\alpha)=(1-\alpha)\left[w_{s} \beta\left(1-\tau^{u}\right)-h(1-s)(1+i)\right] \\
\rho^{u}(\beta)=\frac{(1-\alpha)\left[h(1-s)(1+i)-w_{s} \beta\left(1-\tau^{u}\right)\right]}{(1+i)(1-\alpha)-1} .
\end{gathered}
$$

According to figure 2, in order to find the limit level of wealth of the non-qualified people, the following has to be levelled

$$
\begin{gathered}
b_{u}\left(x_{t}\right)=x_{t} \\
(1-\alpha)\left[\left(x_{t}+w_{u}\right)(1+r)+w_{u}\left(1-\tau^{u}\right)\right]=x_{t} \\
(1-\alpha)\left(x_{t}+w_{u}\right)(1+r)+(1-\alpha) w_{u}\left(1-\tau^{u}\right)=x_{t} \\
(1-\alpha) x_{t}(1+r)+(1-\alpha) w_{u}(1+r)+(1-\alpha) w_{u}\left(1-\tau^{u}\right)=x_{t} \\
(1-\alpha) w_{u}(1+r)+(1-\alpha) w_{u}\left(1-\tau^{u}\right)=x_{t}-(1-\alpha) x_{t}(1+r) \\
(1-\alpha)\left(2+r-\tau^{u}\right) w_{u}=x_{t}[1-(1-\alpha)(1+r)] \\
x_{s s}^{u, u}=\frac{(1-\alpha)\left(2+r-\tau^{u}\right) w_{u}}{1-(1-\alpha)(1+r)} .
\end{gathered}
$$

In order to find the limit level of wealth of the qualified, the following has to be done

$$
\begin{gathered}
b^{s l}\left(x_{t}\right)=x_{t} \\
(1-\alpha)\left\{w_{s} \beta\left(1-\tau^{u}\right)+\left[x_{t}-h(1-s)\right](1+r)\right\}=x_{t}
\end{gathered}
$$




$$
\begin{gathered}
(1-\alpha) w_{s} \beta\left(1-\tau^{u}\right)+(1-\alpha)(1+r) x_{t}-h(1-s)(1-\alpha)(1+r)=x_{t} \\
(1-\alpha)\left[w_{s} \beta\left(1-\tau^{u}\right)-h(1-s)(1+r)\right]=x_{t}-(1-\alpha) x_{t}(1+r) \\
(1-\alpha)\left[w_{s} \beta\left(1-\tau^{u}\right)-h(1-s)(1+r)\right]=x_{t}[1-(1-\alpha)(1+r)] \\
x_{s s}^{s l, u}(\beta)=\frac{(1-\alpha)\left[h(1-s)(1+r)-w_{s} \beta\left(1-\tau^{u}\right)\right]}{(1-\alpha)(1+r)-1} .
\end{gathered}
$$

\subsection{Proof of Lemma 7}

Proof. In order to find the value of $q_{t}$ the following has to be done,

$$
\begin{gathered}
\left.U^{s b}=\ln \left[w_{s} \beta_{i}\left(1-\tau_{t}^{g}\right)+(x-h(1-s))(1+i)\right]+\varepsilon=U^{u}=\ln \left[\left(x+w_{u}\right)(1+r)+w_{u}\right)\right]+\varepsilon \\
w_{s} \beta_{i}\left(1-\tau_{t}^{g}\right)+(x-h(1-s))(1+i)=\left(x+w_{u}\right)(1+r)+w_{u} \\
x(i-r)=w_{u}(2+r)+h(1-s)(1+i)-w_{s} \beta_{i}\left(1-\tau_{t}^{g}\right) \\
q_{t}^{g}(\beta)=\frac{w_{u}(2+r)+h(1-s)(1+i)-w_{s} \beta_{i}\left(1-\tau_{t}^{g}\right)}{i-r} .
\end{gathered}
$$

\subsection{Proof of Lemma 8}

Proof. In order to obtain $\rho$ the following has to be done

$$
\begin{gathered}
x=(1-\alpha)\left[w_{s} \beta\left(1-\tau^{g}\right)+(x-h(s))(1+i)\right] \\
x-x(1+i)(1-\alpha)=(1-\alpha)\left[w_{s} \beta\left(1-\tau^{g}\right)-h(s)(1+i)\right] \\
\rho^{g}(\beta)=\frac{(1-\alpha)\left[h(s)(1+i)-w_{s} \beta\left(1-\tau^{g}\right)\right]}{(1+i)(1-\alpha)-1} .
\end{gathered}
$$

According to figure 2, in order to find the limit level of wealth of the non qualified, the following has to be levelled

$$
\begin{gathered}
b_{u}\left(x_{t}\right)=x_{t} \\
(1-\alpha)\left[\left(x+w_{u}\right)(1+r)+w_{u}\right]=x_{t} \\
(1-\alpha)\left(x+w_{u}\right)(1+r)+(1-\alpha) w_{u}=x \\
(1-\alpha) x(1+r)+(1-\alpha) w_{u}(1+r)+(1-\alpha) w_{u}=x \\
(1-\alpha) w_{u}(1+r)+(1-\alpha) w_{u}=x-(1-\alpha) x(1+r)
\end{gathered}
$$




$$
\begin{gathered}
(1-\alpha)(2+r) w_{u}=x_{t}[1-(1-\alpha)(1+r)] \\
x_{s s}^{u, g}=\frac{(1-\alpha)(2+r) w_{u}}{1-(1-\alpha)(1+r)} .
\end{gathered}
$$

In order to find the limit level of wealth those qualified, the following has to be done

$$
\begin{gathered}
b^{s l}\left(x_{t}\right)=x_{t} \\
(1-\alpha)\left\{w_{s} \beta_{i}\left(1-\tau^{g}\right)+(x-h(1-s))(1+r)\right\}=x_{t} \\
(1-\alpha) w_{s} \beta\left(1-\tau^{g}\right)+(1-\alpha)(1+r) x_{t}-h(1-s)(1-\alpha)(1+r)=x_{t} \\
(1-\alpha)\left[w_{s} \beta\left(1-\tau^{g}\right)-h(1-s)(1+r)\right]=x_{t}-(1-\alpha) x_{t}(1+r) \\
(1-\alpha)\left[w_{s} \beta\left(1-\tau^{g}\right)-h(1-s)(1+r)\right]=x_{t}[1-(1-\alpha)(1+r)] \\
x_{s s}^{s l, g}(\beta)=\frac{(1-\alpha)\left[h(1-s)(1+r)-w_{s} \beta\left(1-\tau^{g}\right)\right]}{(1-\alpha)(1+r)-1} .
\end{gathered}
$$

\subsection{Proof of Proposition 1}

Proof. First, it is possible to state clearly that

$$
\rho^{g}(\beta=0)=\rho^{u}(\beta=0) .
$$

In addition, we need to show that

$$
\beta\left(\rho^{u}=0\right)<\beta\left(\rho^{g}=0\right),
$$

note that,

$$
\begin{aligned}
\frac{h(1-s)(1+i)}{\left(1-\tau^{u}\right) w_{s}} & <\frac{h(1-s)(1+i)}{\left(1-\tau^{g}\right) w_{s}} \\
\tau^{g} & >\tau^{u}
\end{aligned}
$$

replacing

$$
\begin{gathered}
\frac{\left(1+i_{g}\right) h s}{w_{s}}>\frac{\left(1+i_{g}\right) h s\left[\int_{\beta_{\min }}^{\beta_{\max }} \int_{\rho^{u}(\beta)}^{\infty} m_{t}(x \| \beta) d x d \beta\right]}{\left[w_{s}\left[\int_{\beta_{\min }}^{\beta_{\max }} \int_{\rho^{u}(\beta)}^{\infty} m_{t}(x \| \beta) d x d \beta\right]+w_{u}\left(1-P_{e e}\right)\right]} \\
\int_{\beta_{\min }}^{\beta_{\max }} \int_{\rho^{u}(\beta)}^{\infty} m_{t}(x \| \beta) d x d \beta+\frac{w_{u}\left(1-P_{s s}\right)}{w_{s}}>\int_{\beta_{\min }}^{\beta_{\max }} \int_{\rho^{u}(\beta)}^{\infty} m_{t}(x \| \beta) d x d \beta \\
\frac{w_{u}\left(1-P_{s s}\right)}{w_{s}}>0
\end{gathered}
$$

that is true due to the assumption 4. 


\subsection{Proof of Proposition 2}

Proof. First, it is possible to state that

$$
\begin{gathered}
\rho^{g}(\beta=0)=\rho^{u}(\beta=0)<\rho^{a}(\beta=0) \\
\frac{(1-\alpha) h(1-s)(1+i)}{[(1-\alpha)(1+i)-1]}<\frac{(1-\alpha) h(1+i)}{[(1-\alpha)(1+i)-1]} \\
(1-s)<1 \\
s>0 .
\end{gathered}
$$

In addition,

$$
\beta\left(\rho^{g}=0\right)<\beta\left(\rho^{a}=0\right),
$$

replacing

$$
\begin{gathered}
\frac{h(1-s)(1+i)}{\left(1-\tau^{g}\right) w_{s}}<\frac{h(1+i)}{w_{s}} \\
(1-s)<\left(1-\tau^{g}\right) \\
s>\tau^{g} \\
w_{s} \widehat{\widehat{\beta}}^{g}>\left(1+i_{g}\right) h,
\end{gathered}
$$

that is true due to the assumptions 3 .

\subsection{Proof of Proposition 3}

Proof. It is proved that

$$
x_{s s}^{u, a}=x_{s s}^{u, g}=\frac{(1-\alpha)(2+r) w_{u}}{1-(1-\alpha)(1+r)} .
$$

In turn,

$$
\begin{gathered}
x_{s s}^{u, u}=\frac{(1-\alpha)\left(2+r-\tau^{u}\right) w_{u}}{1-(1-\alpha)(1+r)}<x_{s s}^{u, a}=x_{s s}^{u, g} \\
\frac{(1-\alpha)\left(2+r-\tau^{u}\right) w_{u}}{1-(1-\alpha)(1+r)}<\frac{(1-\alpha)(2+r) w_{u}}{1-(1-\alpha)(1+r)} \\
\left(2+r-\tau^{u}\right) w_{u}<(2+r) w_{u} \\
\tau^{u} w_{u}>0 .
\end{gathered}
$$




\subsection{Proof of Proposition 4}

Proof. It is confirmed that $x_{s s}^{s l, u}>x_{s s}^{s l, g}$ provided the following takes place

$$
\begin{aligned}
& x_{s s}^{s l, u}(\widehat{\beta})=\frac{(1-\alpha)\left[w_{s} \widehat{\beta}\left(1-\tau^{u}\right)-h(1-s)(1+r)\right]}{1-(1-\alpha)(1+r)}> \\
& x_{s s}^{s l, g}(\widehat{\beta})=\frac{(1-\alpha)\left[w_{s} \widehat{\beta}\left(1-\tau^{g}\right)-h(1-s)(1+r)\right]}{1-(1-\alpha)(1+r)} \\
& \frac{(1-\alpha)\left[w_{s} \widehat{\beta}\left(1-\tau^{u}\right)-h(1-s)(1+r)\right]}{1-(1-\alpha)(1+r)}> \frac{(1-\alpha)\left[w_{s} \widehat{\beta}\left(1-\tau^{g}\right)-h(1-s)(1+r)\right]}{1-(1-\alpha)(1+r)} \\
& {\left[w_{s} \widehat{\beta}\left(1-\tau^{u}\right)-h(1-s)(1+r)\right] }>\left[w_{s} \widehat{\beta}\left(1-\tau^{g}\right)-h(1-s)(1+r)\right] \\
& w_{s} \widehat{\beta} \tau^{g}>w_{s} \widehat{\beta} \tau^{u} \\
& \tau^{g}>\tau^{u},
\end{aligned}
$$

that is stated in the proof of Proposition 1.

\subsection{Proof of Proposition 5}

Proof. It is confirmed that $x_{s s}^{s l, a}>x_{s s}^{s l, g}$ since $i_{g}>r$ (notice that here the comparison is made for $\beta$ considering the level of the mean of those who study in the system of graduates taxation).

$$
\begin{gathered}
x_{s s}^{s l, a}\left(\widehat{\beta}^{g}\right)=\frac{(1-\alpha)\left[w_{s} \widehat{\beta}^{g}-h(1+r)\right]}{1-(1-\alpha)(1+r)}>x_{s s}^{s l, g}\left(\widehat{\beta}^{g}\right)=\frac{(1-\alpha)\left[w_{s} \widehat{\beta}^{g}\left(1-\tau^{g}\right)-h(1-s)(1+r)\right]}{1-(1-\alpha)(1+r)} \\
\frac{(1-\alpha)\left[w_{s} \widehat{\beta}^{g}-h(1+r)\right]}{1-(1-\alpha)(1+r)}>\frac{(1-\alpha)\left[w_{s} \widehat{\beta}^{g}\left(1-\tau^{g}\right)-h(1-s)(1+r)\right]}{1-(1-\alpha)(1+r)} \\
{\left[w_{s} \widehat{\beta}^{g}-h(1+r)\right]>\left[w_{s} \widehat{\beta}^{g}\left(1-\tau^{g}\right)-h(1-s)(1+r)\right]} \\
w_{s} \widehat{\beta}^{g} \tau^{g}>h s(1+r) \\
w_{s} \widehat{\beta}^{g} \frac{\left(1+i_{g}\right) h s P_{s s}}{w_{s} P_{s s} \widehat{\beta}^{g}}>h s(1+r) \\
\left(1+i_{g}\right)>(1+r) \\
i_{g}>r .
\end{gathered}
$$




\section{Appendix B}

\subsection{Inequality}

\section{Case 1}
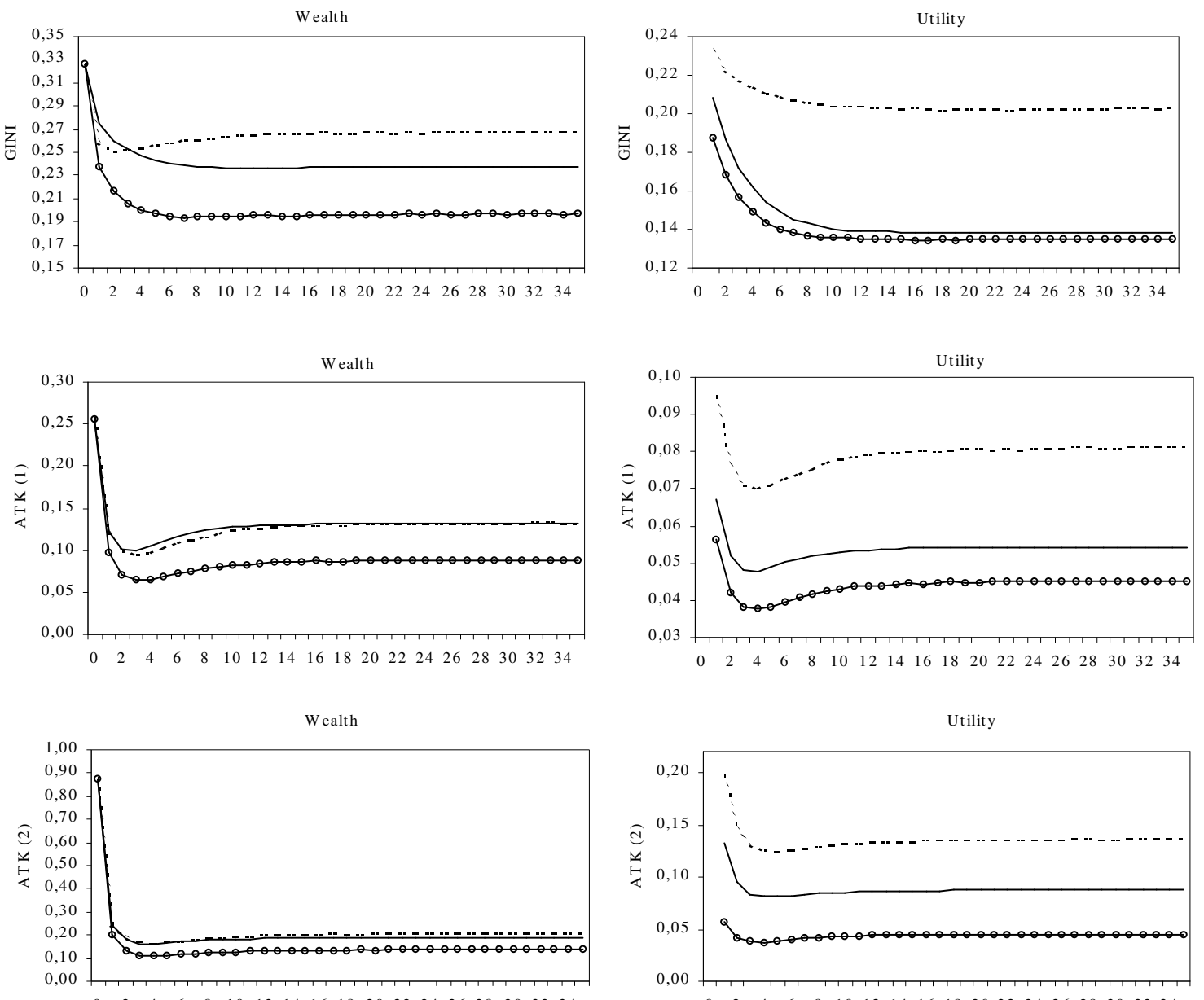

$\begin{array}{llllllllllllllllll}0 & 2 & 4 & 6 & 8 & 10 & 12 & 14 & 16 & 18 & 20 & 22 & 24 & 26 & 28 & 30 & 32 & 34\end{array}$

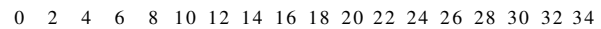

Fee $\quad$ F...... Uniform

—_ Graduates

Figure 3: 


\section{Case 2}
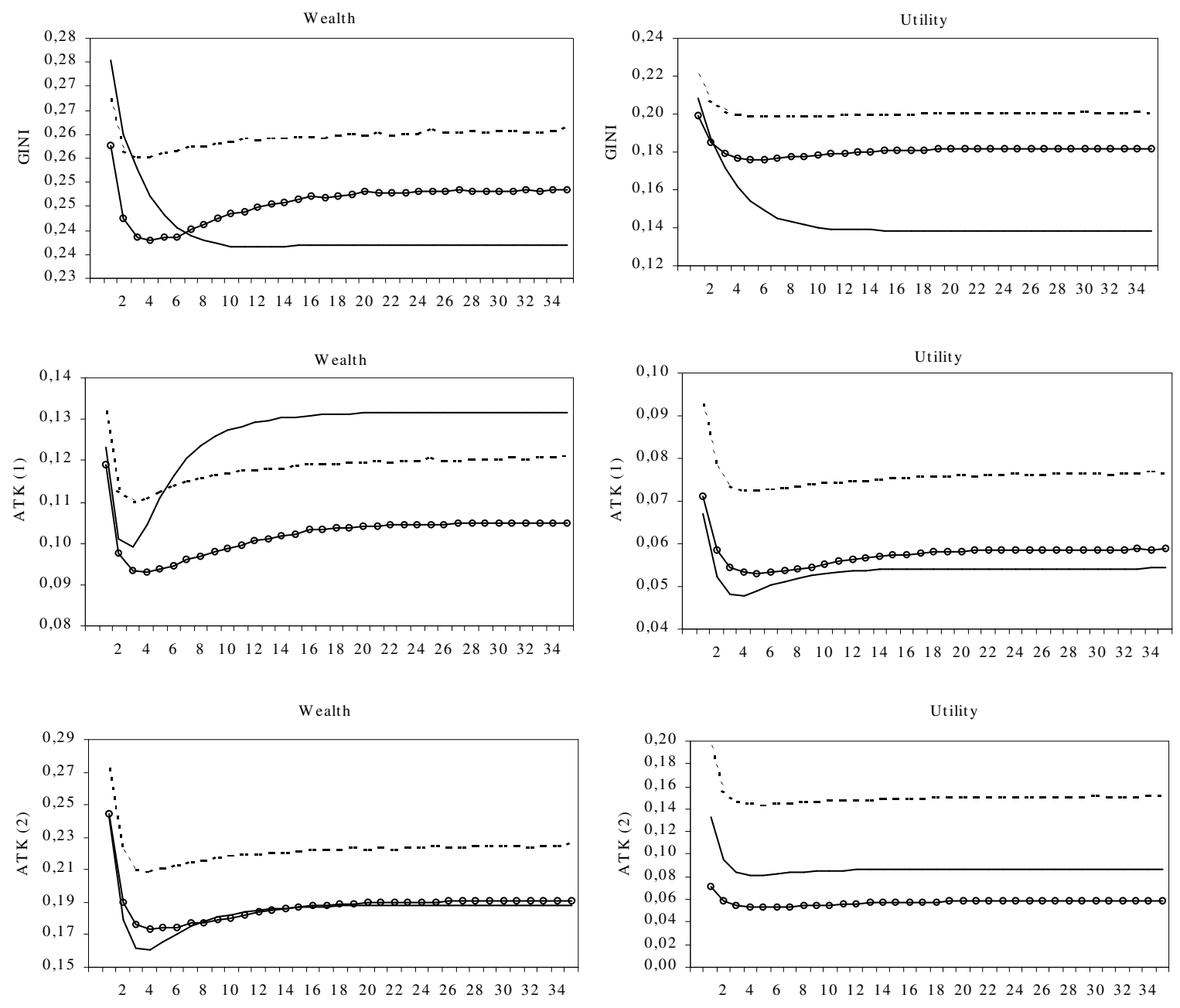

Fee

- Uniform

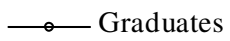

Figure 4: 


\subsection{Poverty}

\section{Case 1}
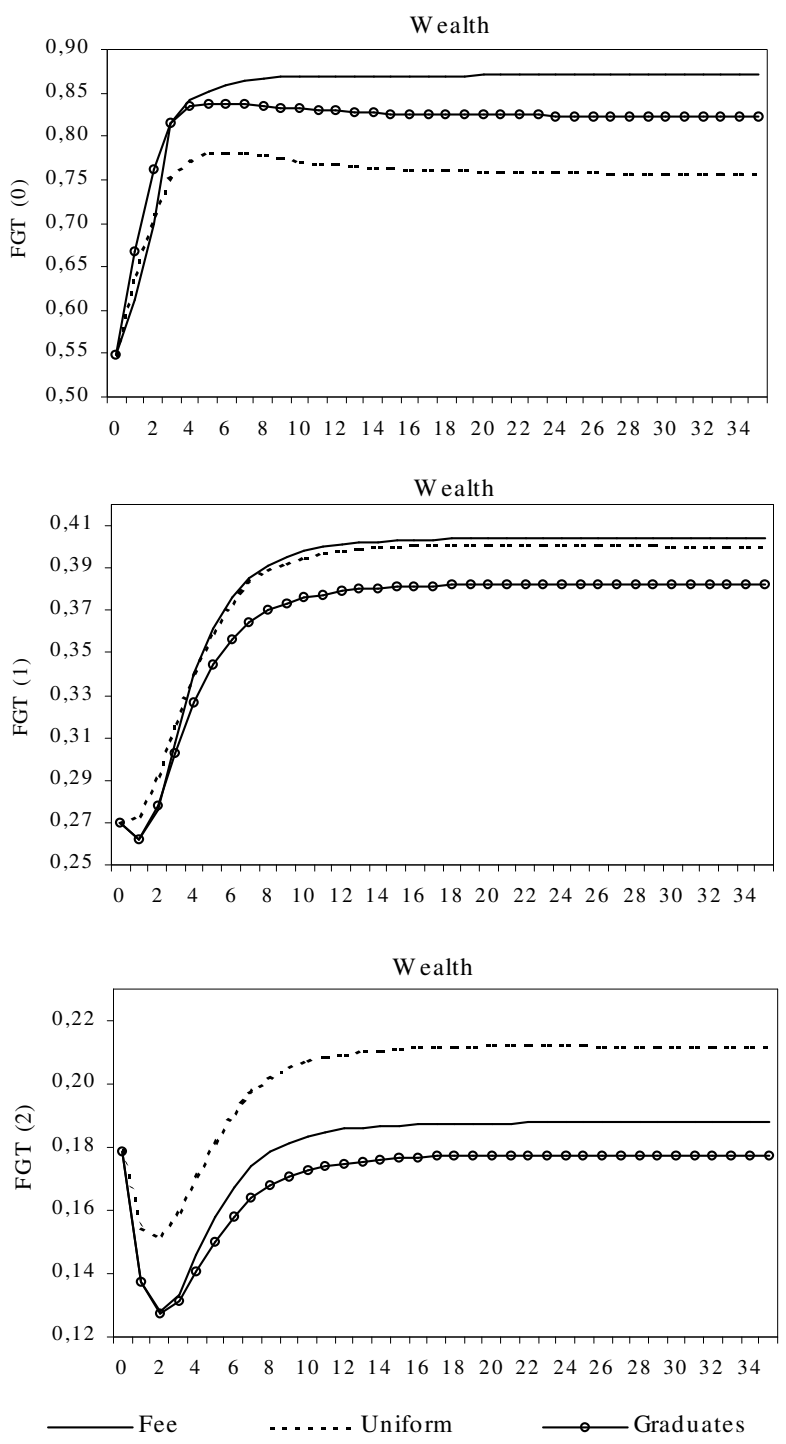

Figure 5: 


\section{Case 2}
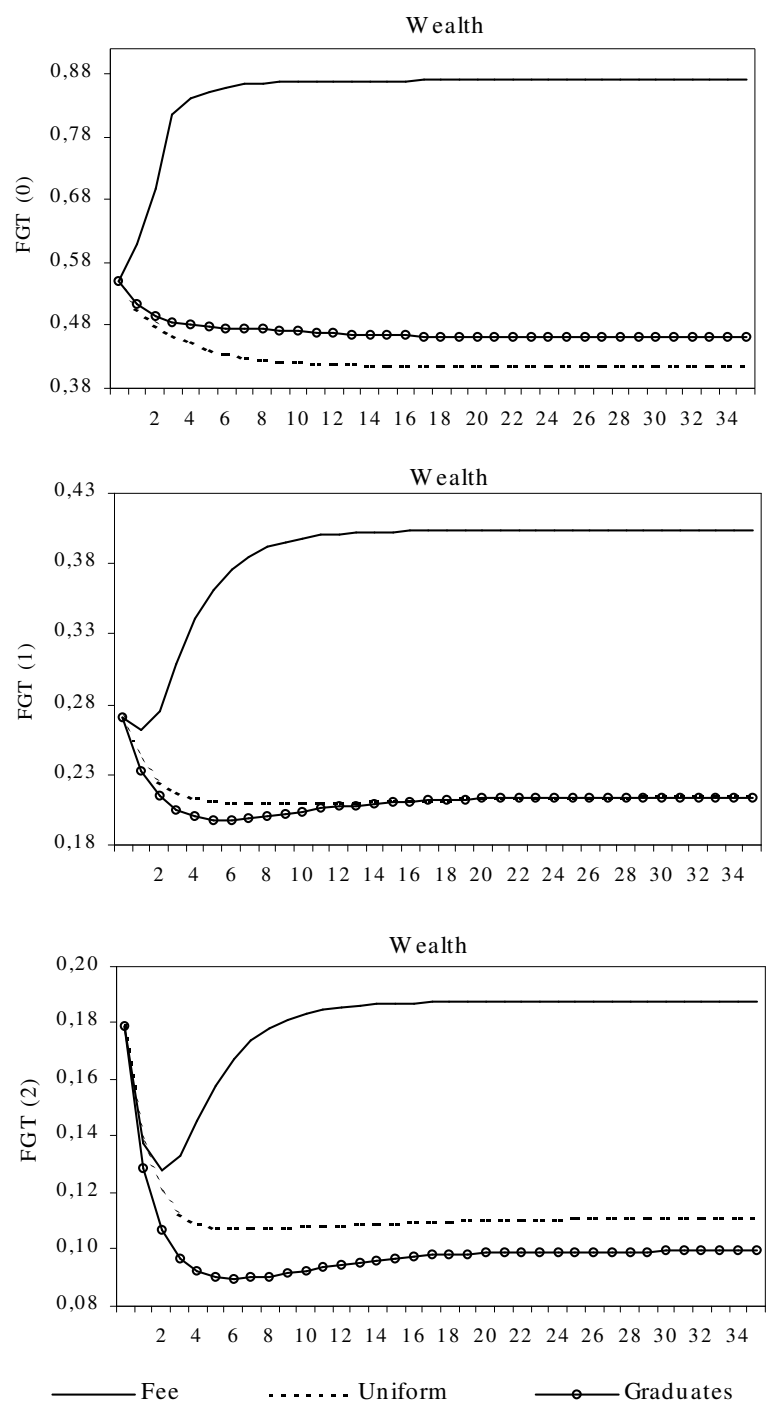

Figure 6: 


\subsection{Average of wealth and utility}

\section{Case 1}
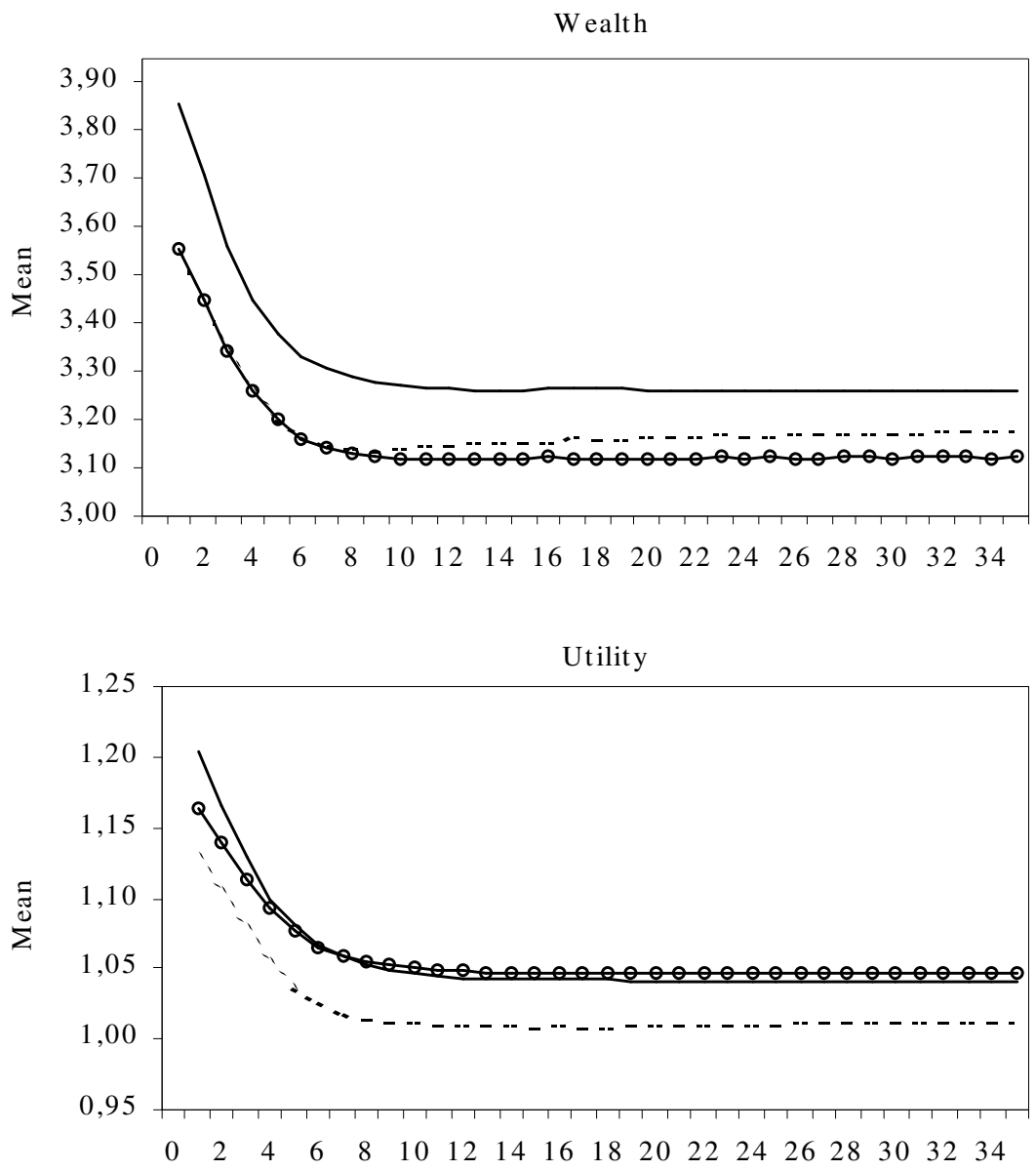

Figure 7: 


\section{Case 2}
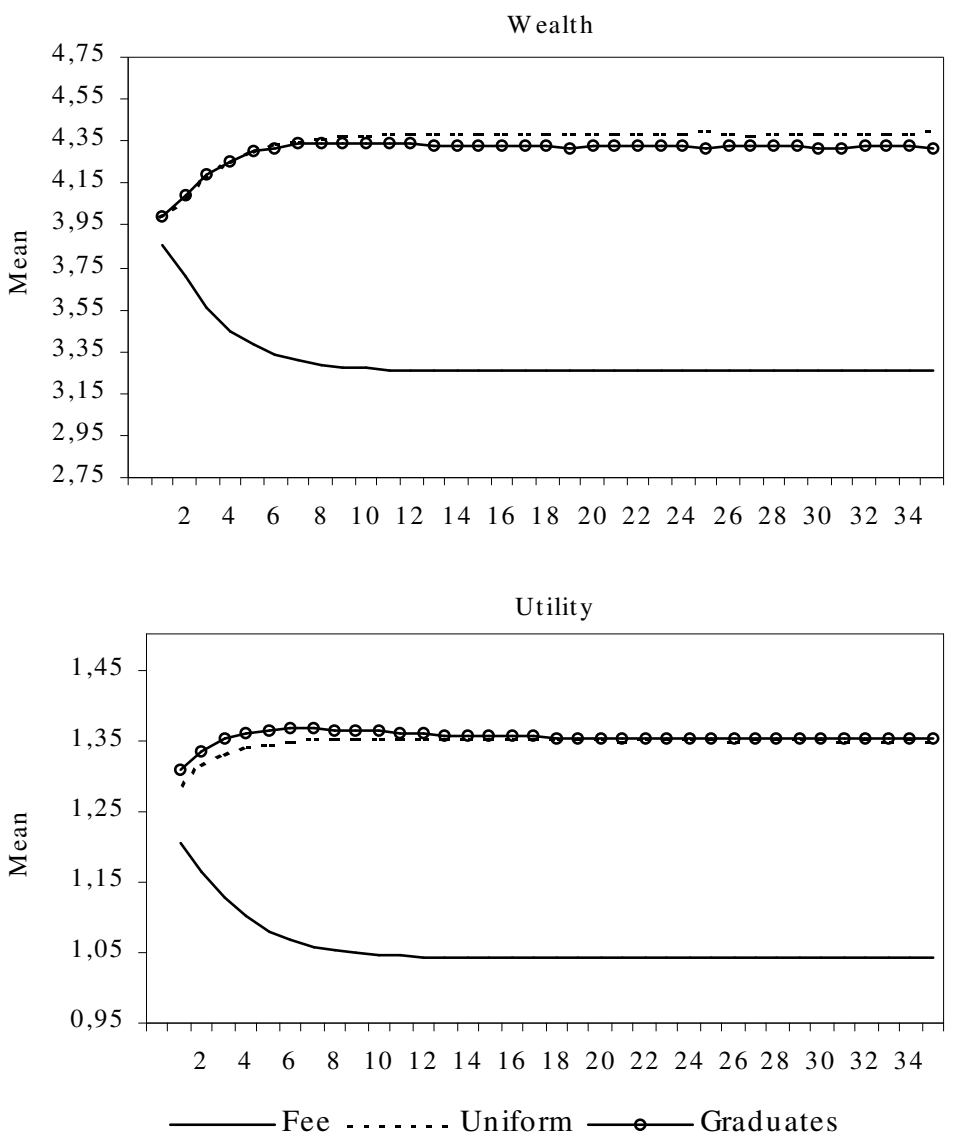

Figure 8: 


\subsection{Welfare}

\section{Case 1}
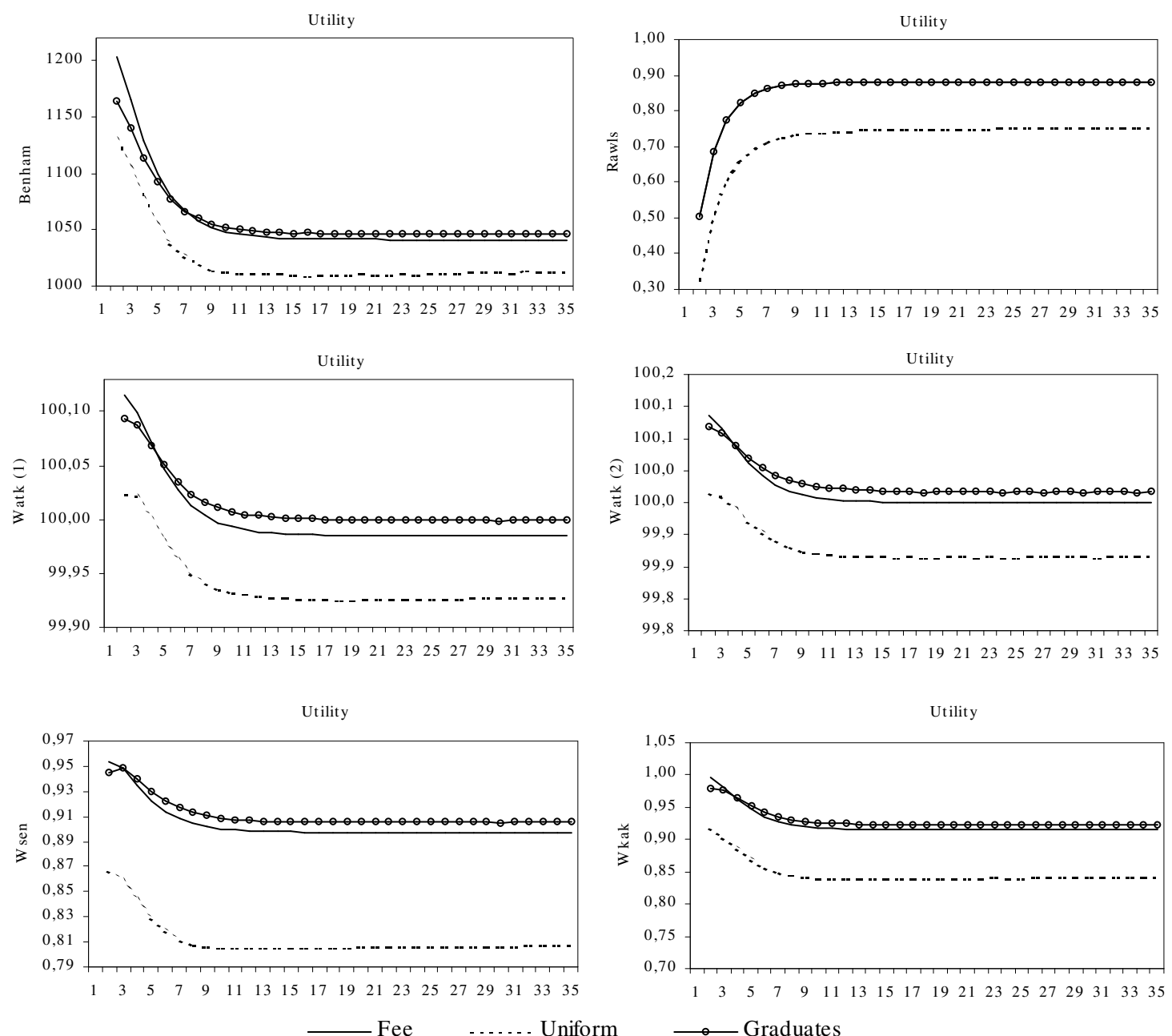

Figure 9: 


\section{Case 2}
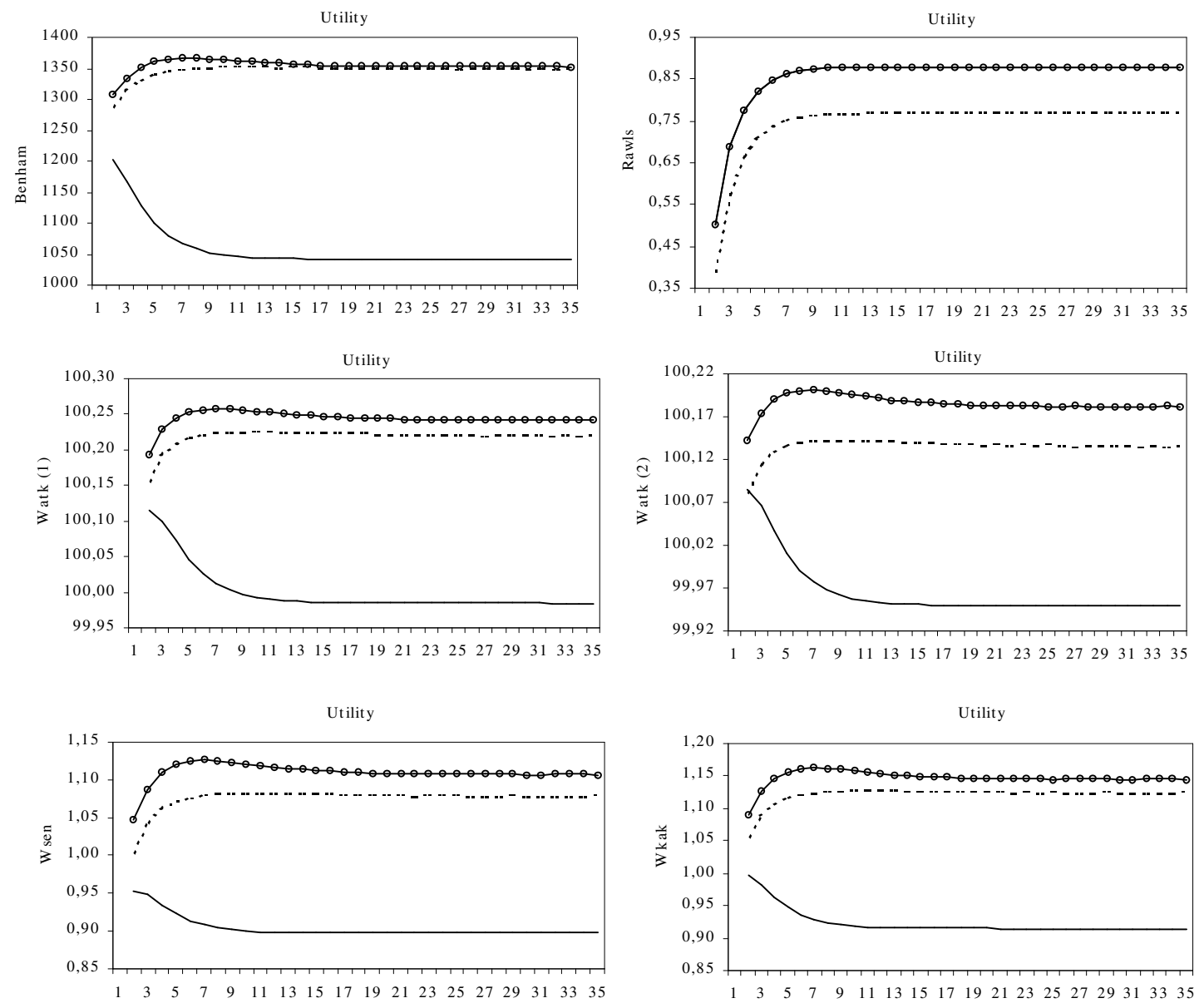

- Fee $\quad$....... Uniform

$\longrightarrow$ Graduates

Figure 10: 


\section{References}

[1] Acemoglu, D. (2001). "Credit Market Imperfections and Persistent Unemployment". MIT Working Paper.

[2] Aghion and Howitt (1998). "Endogenous Growth Theory". MIT Press.

[3] Becker, G. (1962). "Investiment in human capital: A theorical analysis", Journal of Political Economy, 70, 9-49.

[4] Browning M., Hansen L. and Heckman J. (1999). "Micro Data and General Equilibrium Models". Handbook of Macroeconomics. Volume 1A, 543-625.

[5] Caucutt E. and Kumar K. (2000). "Higher Education Subsidies and Heterogeneity: A Dynamic Analysis". Working Paper Rochester Center for Economic Research.

[6] Chen Hung- ju C. (2002) "Educational Systems, Growth and Income Distribution: A Quantitative Study". Working Paper UCLA.

[7] Chiu H. (1998). "Income Inequality, Human Capital Accumulation and Economic Performance". The Economic Journal, 108, 44-59.

[8] Ennis H. and Porto A.(2001). "Igualdad de Oportunidades e Ingreso a la Universidad Pública en la Argentina". Documento de Trabajo No30. Departamento de Economía, UNLP.

[9] Foster, Greer y Thorbecke (1984). "A class of decomposable poverty measures". Econometrica 52, 761-765

[10] Galor O. and Zeira J.(1993) "Income distribution and macroeconomics", Review of Economic Studies, 60, 35-52.

[11] Gasparini L. (1998). "La incidencia impositiva del sistema tributario en Argentina. En FIEL, La reforma tributaria en Argentina.

[12] Gasparini L. y Sosa Escudero W. (2001). "Assessing aggregate welfare: growth and inequality in Argentina". Cuadernos de Economía (Latin American Journal of Economics) 38, No 113. 
[13] Ghatak M., Morelli M. and Sjöström T. (2001). "Credit Rationing, Wealth Inequality, and Allocation of Talent". Working Paper Pennsylvania State University.

[14] Glomm G. and Ravikumar B. (1992). "Public vs. Private Investment in Human Capital: Endogenous Growth and Income Inequality". Journal of Political Economy 100 (4), 106-112.

[15] Moav O. (2000). "Income Distribution and Macroeconomics: Convex Technology and the Role of Intergenerational Transfers". Working Paper Hebrew University of Jerusalem.

[16] Mulligan, C. (1997). "Parental priorities and economic inequality". Chicago. University of Chicago Press.

[17] Nelson and Phelps (1966). "Investment in Humans, Technological Diffusion, and Economic Growth". American Economic Reviews 61: 69-75.

[18] Lucas Jr. R. (1988). "On the mecanics of economic development", Journal of Monetary Economics, 22, 3-42.

[19] Rillaers A. and Durán J. (2002). "Idiosyncratic productivity shocks, borrowing limits, and investment in human capital". Working Paper IRES.

[20] Romero L. (2004). "Education Subsidies, Income Inequality and Intergenerational Mobility". Working Paper Universidad Carlos III de Madrid. 